Florida International University

FIU Digital Commons

FIU Electronic Theses and Dissertations

University Graduate School

3-29-2002

\title{
What secondary english to speakers of other languages (ESOL) teachers know about social and academic language and instructional strategies for limited english proficient students
}

Judy Chin

Florida International University

DOI: $10.25148 /$ etd.FI14060806

Follow this and additional works at: https://digitalcommons.fiu.edu/etd

Part of the Curriculum and Instruction Commons

\section{Recommended Citation}

Chin, Judy, "What secondary english to speakers of other languages (ESOL) teachers know about social and academic language and instructional strategies for limited english proficient students" (2002). FIU Electronic Theses and Dissertations. 2337.

https://digitalcommons.fiu.edu/etd/2337 


\section{FLORIDA INTERNATIONAL UNIVERSITY}

Miami, Florida

WHAT SECONDARY ENGLISH TO SPEAKERS OF OTHER LANGUAGES (ESOL) TEACHERS KNOW ABOUT SOCIAL AND ACADEMIC LANGUAGE AND INSTRUCTIONAL STRATEGIES FOR LIMITED ENGLISH PROFICIENT STUDENTS

A dissertation submitted in partial fulfillment of the requirements for the degree of DOCTOR OF EDUCATION in CURRICULUM AND INSTRUCTION by Judy Chin 


\section{To: Dean Linda Blanton}

College of Education

This dissertation, written by Judy Chin, and entitled What Secondary English to Speakers of Other Languages (ESOL) Teachers Know About Social and Academic Language and Instructional Strategies for Limited English Proficient Students, having been approved in respect to style and intellectual content, is referred to you for judgment.

We have read this dissertation and recommend that it be approved.

Stephen M. Fain

Sandra H. Fradd

Judith J. Slater, Major Professor

Date of Defense: March 29, 2002

The dissertation of Judy Chin is approved.

Dean Linda Blanton

College of Education

Dean Douglas Wartzok University Graduate School

Florida International University, 2002 
(C) Copyright 2002 by Judy Chin

All rights reserved. 


\section{DEDICATION}

I dedicate this dissertation to my students and my ESOL colleagues. My students challenge and inspire me. My colleagues' dedication and professionalism sustain me. 


\section{DEDICATION}

I dedicate this dissertation to my students and my ESOL colleagues. My students challenge and inspire me. My colleagues' dedication and professionalism sustain me. 


\section{ACKNOWLEDGMENTS}

I would like to acknowledge all the members of my committee for their insights and direction. First of all, I want to thank Dr. Stephen Fain for what he has taught me about personal commitment. Additionally, his cogent comments during this process provided not only another perspective, but also a counter balance. Dr. Abbas Tashakkori's observations and highly focused questions from the inception of the study to its completion were greatly appreciated. Dr. Sandra Fradd, whose broad knowledge and vast experience in the field of second language acquisition, provided critical commentary and was a constant support. Finally, I would like to thank Dr. Judith Slater, not only for her reading, editing, and consulting of the manuscript, but also for her intense dedication to the field of Curriculum and Instruction which imbues her students with a desire to be among those who can and should make a difference. 


\section{ABSTRACT OF THE DISSERTATION}

\section{WHAT SECONDARY ENGLISH TO SPEAKERS OF OTHER LANGUAGES (ESOL)}

TEACHERS KNOW ABOUT SOCIAL AND ACADEMIC LANGUAGE AND INSTRUCTIONAL STRATEGIES FOR LIMITED ENGLISH PROFICIENT

STUDENTS

by

Judy Chin

Florida International University, 2002

Miami, Florida

Professor Judith J. Slater, Major Professor

The purpose of this study was to examine what secondary English to Speakers of Other Languages (ESOL) teachers understand about social and academic language, what instructional strategies they use for Limited English Proficient (LEP) students, and how these concepts are operationalized in their daily practice.

This was a mixed method study incorporating both quantitative and qualitative data collection and interpretation. Written questionnaires and individual interviews addressed the questions on teachers' definitions of social and academic language and their strategy use. Classroom observations provided verification of their definitions and their descriptions of instruction for academic language.

Findings indicated that teachers' definitions of social and academic language were still developing and that there were ambiguities in identifying examples of social and 
academic language. The use of graphic organizers or visual supports, groups or peer partners, role play or drama, and modeling were the strategies teachers consistently listed for beginner, intermediate, advanced and multiple level classes. Additionally, teachers' descriptions of their instruction were congruent with what was observed in their classroom practice.

It appeared that this population of secondary ESOL teachers was in the process of evolving their definitions of social and academic language and were at different stages in this evolution. Teachers' definitions of language influenced their instruction. Furthermore, those who had clear constructs of language were able to operationalize them in their classroom instruction. 
I. STATEMENT OF THE PROBLEM 1

Background 2

Definition of Language Proficiency 3

Academic Language and Instruction $\quad 7$

Professional Preparation $\quad 8$

$\begin{array}{ll}\text { Purpose of Study } & 10\end{array}$

Research Question 11

$\begin{array}{ll}\text { Limitations of Study } & 12\end{array}$

Definitions of Terms 13

Summary 14

II. REVIEW OF THE LITERATURE 15

Defining Social and Academic Language $\quad 15$

LEP Students and Academic Achievement 24

Instructional Strategies $\quad 27$

Teachers of LEP Students $\quad 30$

Teacher Knowledge and Practice $\quad 32$

Summary $\quad 36$

III. RESEARCH METHODOLOGY 37

Description of Methodology $\quad 37$

Research Context $\quad 39$

Participants $\quad 40$

Procedure $\quad 40$

Analysis and Coding $\quad 44$

Summary $\quad 45$

IV. FINDINGS 46

Demographic Description 46

Differentiation of Social and Academic Language 51

Use of Instructional Strategies 63

Descriptions of Instruction $\quad 70$

Differentiations of Teachers' Strategy Use $\quad 75$

Congruence Between Descriptions and Practice 76

Summary $\quad 85$

$\begin{array}{ll}\text { V. DISCUSSION } & 87\end{array}$

Study Focus $\quad 87$

Methodology $\quad 89$

Summary of Findings $\quad 89$

Discussion 91 
Relationship to Prior Research and Theoretical Implications

Implications from Teacher Population

Conclusions

96

Implications for Practice

98

Implication of Definition

99

Recommendations

99

Recommendations for Further Studies

LIST OF REFERENCES 


\section{LIST OF TABLES}

TABLE

PAGE

1. Teacher Participation in Questionnaire, Interview and Observation by Region

2. Teachers' Years of Experience in Teaching ESOL 48

3. Native Language Background of Teacher Participants 48

4. Method of Endorsement or Certification in ESOL 49

5. Categorizations for Social and Academic Language from 53 Teacher Questionnaires

6. Teachers' Categorization of Language Examples on Questionnaire 62

7. Teachers' Ratings of Academic Language from Questionnaire 63 Language Examples

8. Frequency Use of Strategies for LEP Students 65

9. Teachers' Listing of Strategies or Tasks/Activities Based 66 on Level of English Language Proficiency

10. Four Strategies Used for Various Levels of English 67 Language Proficiency 


\section{CHAPTER I}

\section{STATEMENT OF THE PROBLEM}

Being proficient in a language means being communicatively competent (Canale \& Swain, 1980). Initially this term was relegated to grammatical competence, sociolinguistic competence, and strategic competence, but as the conceptualization has grown into acceptance and use, it has become more comprehensive and expanded to include discourse competence. The skills that are required for communicative competence in social settings differ from the communicative competence required in academic settings.

One of the goals of the educational system is that students be able to make use of decontextualized language, that is, be able to use language alone as a tool for learning or reading and listening; and to be able to use language alone as a tool for conceptualizing, drawing abstract generalizations, and expressing complex relationships in speaking and writing. (Swain, 1981, p.5)

The expanded definition and conceptualization of language proficiency has direct ramifications on the requisite skills needed for Limited English Proficient (LEP) students to be successful academically. This in turns impacts the resultant instructional expectations and decisions arising from those needs. The importance of language proficiency and communicative competence has long been recognized, but teacher preparation and student-focused curricula may not have kept pace with the conceptualization of language. 


\section{Background}

In 1968 the United States government first recognized the educational disadvantages encountered by non-English speaking students and established federal policy for this population. Known as the Title VII amendment, or the Bilingual Education Act of the Elementary and Secondary Education Act, funding was provided for programs for non-English speaking children of low-income families. Reauthorization of this act in 1974 removed the low-income requirement and opened program participation to all students who needed to learn English. In the same year there was a Supreme Court ruling in Lau v. Nichols (1974). This case is considered to be a major influence nationally in the implementation of bilingual educational programs (Fradd \& Vega, 1987).

Over the past thirty-five years the demographics within the United States have changed significantly and federal policy for LEP students has evolved, partially as the result of legislation and partly in response to judicial actions. Nationally, between the years of 1985 and 1994 there was an average increase of nearly $10 \%$ annually in the LEP population. Across the nation there is a wide variety of program models developed for these students with an equally broad usage and implementation of instructional strategies (Kuhlman \& Murray, 2000).

The results from the 2000 census indicate that the United States is growing more rapidly than had previously been anticipated. This growth is thought to be attributable to increased immigration, higher birth rates amongst recent immigrants, and increased birth rates from the"baby boomer" generation (Hampson, 2001). In the previous census the language-minority school-age population was 9.9 million, close to $22 \%$ of the total 
population (Anstrom, 1996). Between 1985 and 1995 estimates are that the LEP student population increased by $109 \%$ (Snow, 2000). Given that overall population counts are now higher, it can be assumed that the school-age population has also grown and with it the number of language minority students. Language minority, as defined in that census, referred to individuals living in households in which a language other than English is spoken. Subsumed within this group is the Limited English Proficient population. Most individual states define their population using the federal terminology or a simplified version of it (Cheung, \& Solomon, 1991). That definition has not remained constant and has changed over the years as research has broadened understanding of second language acquisition.

\section{Definition of Language Proficiency}

Prior to 1964, issues of educational opportunity for limited English proficient students had not been addressed by the federal government (Fradd \& Vega, 1987). The federal definition has changed since programs were first begun for these students with the inception of the Bilingual Education Act in 1968. At that time the term limited English speaking ability (LESA) was used. As it implies, speaking was the intended instructional focus. Through the 1978 amendments of this act, the definition expanded to include those who had sufficient difficulty in reading, writing, or understanding the English language. The most recent definition, from the Title VII of the Improving America's School Act (P. L. 103-382, 1994), however is far more specific. It states that a student is LEP if one

has sufficient difficulty speaking, reading, writing, or understanding the English language and whose difficulties may deny such individual the opportunity to learn 
successfully in classrooms where the language of instruction is English or to participate fully in our society due to one or more of the following reason:

Was not born in the United States or whose native language is a language other than English and comes from an environment where a language other than English is dominant;

Is a native American or Alaska native or who is a native resident of the outlying areas and comes from an environment where a language other than English has had significant impact on such individual's level of English language proficiency; or

Is migratory and whose native language is other than English and comes from an environment where a language other than English is dominant. (P.L. 103-382, 1994)

The changing definition reflects various conceptualizations of the dimensions of language proficiency from the research in the field of second language acquisition (SLA) over the past thirty years.

This more expansive view of language proficiency is one of the elements that has been crafted into the Florida Consent Decree. This decree is an agreement that occurred as a result of a class action suit brought against the state Board of Education on behalf of LEP students who were not receiving full access to educational programs in central Florida. The decree has been the legal framework for educational practice for LEP students within this state (LULAC v. Florida Department of Education, 1990). It mandated many changes and brought more into focus the level of proficiency necessary for academic success for LEP students. With the passage of Transforming Florida's Schools Bill (CS/HB 751, 1999) in the 1999 Florida Legislative Session, all students are required to demonstrate skills to a specific performance level in order to be promoted. Additionally, high school students must take the High School Competency Test (HCST) to determine eligibility for graduation. By the year 2003 the Florida Comprehensive Assessment Test (FCAT) will replace the HCST. These current state reforms in 
education in regard to standardized assessments present additional responsibilities and accountability for teachers of LEP students in the content area of language arts/English. This emphasis on accountability is echoed throughout the nation as a result of reform movements.

Curriculum makers have responded to the evolving and expanding understanding of academic language proficiency for LEP students. The state of Florida's Language Arts/English Through ESOL at the middle and high school levels is an example of a curriculum designed to promote the acquisition of academic language proficiency while interfacing language development with language arts or English content instruction.

Within the state of Florida, English for Speakers of Other Languages (ESOL) instruction must integrate instructional techniques of the teaching of English as a foreign language with the instructional requirements of English language arts.

An exclusive reliance on the English-as-a-foreign-language component of ESOL would deprive students of equal access to the language arts curriculum; an exclusive reliance on English language arts requirements may not provide the warranted comprehensible instruction. (B. Garcia, memorandum, June 27, 1995)

The issue of how to interface content instruction and language development is subsumed within a major paradigm shift in the field of second language acquisition. The change in paradigm focuses on the way in which language proficiency has been defined. The definition of either limited English proficiency or full English proficiency directly impacts on funding and programmatic issues not only at the federal level, but also at the state and local levels. Less obviously, successful academic achievement and full participation in society hinge on the level of English language proficiency acquired by second language learners. 
One of the most controversial aspects of bilingual education policy in the United States has been determining exactly what constitutes sufficient proficiency for the student to survive academically in a regular English language classroom. (Allen, Swain, Harley, \& Cummins, 1990, p. 8)

For many years, the assessment of language proficiency for LEPs was defined in terms of oral language proficiency which was more observable through discrete point measures: morphology, phonology, syntax and semantics. But as the field of second language acquisition has grown and developed, the concept of what constitutes language proficiency has also changed. Discrete measures have become a part of a more complex definition (TESOL, 1997). In its simplest form, language proficiency could be described as the ability to comprehend and communicate in oral and written modes in various contexts. This, however, is not sufficient to understand the complexities of second language acquisition, and therefore, the incumbent expectations for teachers who instruct the LEP population. One of the earliest to postulate two distinct aspects of language proficiency was Cummins $(1979,1980,1981)$. He proposed that proficiency be thought of as including social language and academic language. Social language encompasses the language proficiency required in daily communicative contexts and is, for the most part, dependent on the environment and culture in which it occurs (Lee \& Fradd, 1996). Cummins coined the term "basic interpersonal communication skills" (BICS) to refer to the speaker's ability to communicate with others in context-embedded, concrete interactions. Academic language or "cognitive academic language proficiency" (CALP) is required to interact in academic contexts where information is dependent on language that is context reduced or decontextualized (Cummins, 1979). Academic language is more cognitively demanding and more complex linguistically than social language. 
Acquiring academic language proficiency means that students must have knowledge of sociolinguistic styles: using language in various social and academic contexts, understanding of the social register; text structure (understanding that there are a variety of ways texts are organized); content schema; an awareness of the language system itself (metalinguistic knowledge); and also their own language processing (metacognitive knowledge) (Fradd \& McGee, 1994).

\section{Academic Language and Instruction}

For LEP students, academic language proficiency may take five to seven years to acquire, meaning that they score at the $50^{\text {th }}$ percentile on a standardized instrument (Cummins, 1981). To achieve full proficiency and be totally competitive in academic language may take as long as 10 years (Hakuta, Butler \& Witt, 2000). Academic language proficiency is what is ultimately required to assure success in school.

To make academic instruction more comprehensible and accessible to students of varying English proficiency levels requires teachers to use a variety of instructional strategies. Some of the instructional strategies for this population that are thought to promote learning are: second language instructional strategies, use of visuals and graphic organizers, interactive strategies, activation of prior knowledge and building of content schema and vocabulary development (Gersten \& Baker, 2000). However, the effectiveness of these strategies and how to use them specifically for content while simultaneously using them for language development is an area that has not been extensively explored (Gersten \& Baker, 2000). "Attempts to merge content area instruction with English Language Development (ELD) instruction, while well-intended and conceptually sound, are rarely well-implemented" (Gersten \& Baker, 2000, p. 459). 
The increasingly large LEP population in United States schools requires changes in instructional practices and better preparation of teachers to meet the challenges of educating these students.

\section{Professional Preparation}

Preservice and inservice educational programs have been developed in an attempt to further the knowledge and skills of teachers. As a part of their training, ESOL certified or endorsed teachers learn how to modulate content and language development to provide an instructional environment that promotes academic learning while facilitating English language development (Gersten \& Baker, 2000).

Regardless of whether the emphasis is on content area or language development, the current definition of language proficiency requires teachers to be aware of what is involved in the acquisition of second language. Teachers must be able to use various instructional approaches in order to have students acquire social and academic proficiency and for them to achieve in an academic setting. Proficiency in academic language or language which is decontextualized is tantamount to academic achievement for LEP students.

As early as 1983, Florida teachers who taught intensive English to LEP students were required to have an ESOL endorsement. The Consent Decree ruling in 1990 furthered the specialization and certification requirements for ESOL teachers. The requirement for ESOL endorsement was the equivalent of 15 college credit hours or comparable training through inservice district workshops and seminars in the following areas: methods of teaching English to speakers of other languages, ESOL curriculum and materials development, cross-cultural communication and understanding, testing and 
evaluation of ESOL and applied linguistics. The knowledge needed for this certification as evidenced in the course requirements was in the field of second language acquisition and established basic knowledge of teaching English as a second language. At that time specific attention to the delineation between social and academic language was just beginning to be discussed and theorized. Since then there has been more of a focus on academic language proficiency, instruction and expectations for its development through content language arts classes. Although this terminology is now standard in the field, specific identification of academic language or the English language skills LEP students need to acquire for content knowledge are not easily identifiable or discernible.
Although there is a lot of discussion about the need for all children to develop the English language skills required for academic learning and development, few people can identify exactly what those skills consist of or distinguish them from general Standard English skills. To the extent that this matter is examined at all, observers have usually pointed to differences between written and spoken language. However, academic English entails a broad range of language proficiency. We must ask what linguistic proficiencies are required for subject-matter learning... It relies on broad knowledge of words, phraseology, grammar, and pragmatic conventions for expression, understanding, and interpretation (Wong Fillmore \& Snow, 2000, p. 20).

In a survey conducted by Jeff Solomon and Nancy Rhodes of the Center for Applied Linguistics, 66 percent of the educator respondents stated that they explicitly teach academic language, the remainder stated that they did not (Solomon \& Rhodes, 1996b). Nearly 60 percent identified vocabulary as a key feature of academic language while approximately 40 percent described academic language in terms of activities. Although frequently ESOL teachers are cognizant of the differences between social and academic language proficiency and how it affects students' participation in academic tasks (Cummins, 1984; Hakuta, 1986), they many have greater preparation in oral 
language development ( $\mathrm{Au}, 1993)$. In the area of second language acquisition it is assumed that the organization of instruction is dependent on clear understanding of language proficiency, yet among teachers in the field there may be difficulty in specifically defining, identifying, and instructing for academic language proficiency.

Purpose of Study

The purpose of this study is to examine what secondary ESOL teachers know about social and academic language and what instructional strategies they use most frequently to promote academic language development. The field of English as a second language is relatively young, and much is still being learned about best and most effective instructional practices for LEP students. Programming throughout the United States is changing and currently more emphasis is being placed on integrative content and class inclusion then was previously. As efforts are made to deliver content at grade level to these students, their English language development needs must also continue to be addressed. The question of how to do this most successfully still remains to be answered. Because many of the teachers involved in providing instruction to these students have come to the field through a variety of routes, such as from a content area or as a foreign language teacher, their knowledge base in second language acquisition may be equally diverse and discontinuous. Additionally, some teacher education programs use an infusion model in an attempt to address LEP students' needs in the regular classroom. These teachers are not specifically oriented in the field of second language development, but nevertheless are charged with delivering effective instruction to LEP students. This study hopes to describe ESOL secondary school teachers' current knowledge of social and academic language in second language acquisition, identify the instructional 
strategies used most frequently, and determine teachers' perceptions of how they operationalize their knowledge of social and academic language through instructional practice.

The review of literature provides an overview of the development of the definitions of social and academic language through the writings of leading authorities in the field of second language acquisition. Current information on teachers' educational training and backgrounds will also be explored before expanding the discussion to instructional strategies used for LEP students. Although some literature from the nineteen seventies and nineteen eighties will be used to help understand the theoretical basis for this study, the majority of literature will be reflective of research that has occurred in the last ten years. Relevant literature includes published dissertations, periodicals, journals, United States government and agency reports, and books. On-line resources as well as traditional print resources will provide a wide range of materials for the review.

\section{Research Question}

The overarching question for this study is: What do secondary school ESOL teachers know about social and academic language and what instructional strategies do they use most frequently for LEP students? Additionally there are five subsidiary questions:

1. What are the criteria secondary ESOL teachers use to differentiate between social and academic language and what language examples do they identify as being characteristic of each category? 
2. What instructional strategies do secondary ESOL teachers most frequently use to promote academic language with LEP students with beginning, intermediate, advanced or multiple level classes?

3. How do secondary teachers describe their instruction for promoting academic language?

4. Are teachers' descriptions of their strategy use differentiated on the basis of:

(a) the level of students' proficiency in English, (b) teachers' professional preparation, (c) teachers' own language background?

5. Are teachers' descriptions of the strategies they use to promote academic language proficiency congruent with their daily practice?

\section{Limitations of Study}

One of the limitations of this study is that teachers who are not full time ESOL teachers, but who teach LEP students part time, will not be included in the study. Even though all full time ESOL teachers at the secondary level in Miami-Dade County Public Schools will be surveyed, not all will respond. Additionally, this will not provide current information about teachers in the elementary area, who for the most part must infuse strategies throughout their instruction. Another limitation will be in the limited number of teachers interviewed and observed since only those who are willing to participate will be included. Furthermore, this study's generalizability to other teacher populations may be limited since the demographics of Miami-Dade County Public Schools may not be reflective of other school districts and major metropolitan areas in the United States. Nevertheless, since Miami-Dade County is the fourth largest school district in the United States and has a large LEP population, much of what is gleaned can be of value in 
thinking about teachers' knowledge in second language acquisition and also of practices that are thought to promote academic achievement for these students.

Definitions of Terms .

ESOL

This is an acronym for the designated field of English to Speakers of Other Languages (TESOL, 1997, p. 1).

LEP

This is the federal term for Non-English language background speakers who are not fully proficient in English. The acronym stands for Limited English Proficient (Snow, 2000, p. 230).

Academic Language

This term describes "language used in the learning of academic subject matter in formal schooling context: aspects of language strongly associated with literacy and academic achievement, including academic term or technical language, and speech registers related to each field of study" (TESOL, 1997, p. 153).

Social language

This term describes "the aspects of language proficiency strongly associated with basic fluency in face-to-face interaction: natural speech in social interactions, including those that occur in a classroom" (TESOL, 1997, p. 156).

Contextualized or Context Embedded Language

These terms are used to define "Face to face communication, where meaning can be negotiated and is enhanced with a wide range of paralinguistic and situational cues" (Collier, 1987, p. 618), 
These terms refer to "language used in ways to eschew reliance on shared social and physical context in favor of reliance on a context created through the language itself" (Snow, Cancino, DeTemple, Schley, 1991, p. 90).

Instructional Strategy

This term used by the researcher's describes the employment of specific methods or practice to bring about desired outcomes in learners.

\section{Summary}

This chapter provided an introduction and overview of the study. In the second chapter the basis for this study and connections to previous research and theory are presented. 


\section{CHAPTER II}

\section{REVIEW OF THE LITERATURE}

In the review of literature the researcher will provide an overview of the ways academic and social language have been conceptualized in second language acquisition, and a discussion about instructional strategies which are used for LEP students to promote academic language development. Additionally, information on teachers' knowledge in second language acquisition will also be reviewed.

\section{Defining Social and Academic Language}

Human learning presupposes a specific social nature and a process by which children grow into the intellectual life of those around them...The acquisition of language can provide a paradigm for the entire problem of the relation between learning and development. Language arises initially as a means of communication between the child and the people in his environment. Only subsequently, upon conversion to internal speech, does it come to organize the child's thought, that is, become an internal mental function. (Vgotsky, 1962, p. 88)

The development of language is important for social interaction as well as for intellectual growth. It is most critical in the development of learning and thinking (Chamot, n.d.). The social interactionist perspective on learning and language is part of the paradigm that encases much of the research that has been done in the field of second language acquisition. Focusing on the connection between people and their social and psychological worlds, this theoretical view provided an impetus for the shift in emphasis from the teaching process to the learning process and gave way to the development of the field of second language acquisition (Larsen-Freeman \& Long, 1991). 
When children acquire their first language they have usually developed good social language skills by the time they enter school. In terms of function they are usually able to use language to express their personal needs, interact with others, and express their own personal ideas or preferences (Halliday, 1975). They begin to develop more academic language skills such as sequencing, problem solving, imagining, and predicting as they complete their elementary education. They will have begun to bridge from narrative to expository text and understand the difference between topic associative and topic centered discourse from learning to talk, to talking, reading, and writing, to learn (Westby, 1985). By the time they begin high school it is expected that students will be able to extrapolate information from text, understand, analyze, and explain new ideas, and use language appropriately for a variety of tasks in a variety of contexts.

Tasks and contexts are the axis points around which language development spins. Different language tasks require different language skills (Snow, 1983). Some tasks may be extremely demanding cognitively, such as creating a definition (Snow, Cancino, DeTemple, \& Schley, 1991), whereas matching a word in a list is of much lower demand. Additionally, contexts and supports within them either facilitate understanding or create challenges for the language learner. For example, students who use a globe or map to locate cities, or who use pictures and illustrations which provide them with clues, have more understanding or support in expressing ideas than students who need to create an oral argument or persuasive essay on an abstract topic or are asked to analyze analogies. While many second language learners at the secondary level do not possess good social language skills because they are in the beginning process of acquiring English, others have just begun to use language for learning in English, performing academic tasks in a 
less contextualized situation. Still others haven't had the opportunity to develop academic language in their own native language. They are just beginning to discover how language is used for different purposes and requires different types of skills to be able to perform successfully. Nevertheless, all of these students are expected to acquire content on par and at grade level with their non-LEP peers while also acquiring another language if they are to graduate and become participatory members in United States society. Therefore, the ability to use language to learn and to express what is learned is of monumental importance to their eventual success. Indeed it is impossible to extricate language from academic achievement (Fradd \& McGee, 1994).

All language development is important, but the development of academic language especially for secondary students is critical. What is academic language? Where are the demarcations between social and academic language? Questions continue to be raised as to how to identify academic language. It has been proposed that this is not only a question for the area of second language acquisition, but for the field of education in general (Mohan, 1990).

It has been suggested that there needs to be a reconceptualization of academic language since there appears to be a lack of consensus in the field of second language acquisition as to what constitutes academic language (Solomon \& Rhodes, 1995). In reviewing the research Solomon and Rhodes delineated two distinct perspectives on academic language. One view hypothesizes that there are language functions and structures that are specific to content areas and classrooms (Chamot \& O'Malley, 1986; Hamayan \& Perlman, 1990). The other views academic language as being defined by 
contextualization and cognitive demand (Cummins, 1981; Snow, Cancino, DeTemple, \& Schley, 1991).

Any conceptualization of language is multifaceted, multidimensional, yet it is always seen as dichotomous. It is proposed by this researcher, that the dichotomies articulated by various researchers are different is aspect, but not in concept, and can be demonstrated through a discussion of three basic theories developed in the last three decades.

A connection between language and thought was proposed by Oller (1981). He was among the first in the field of second language acquisition to link intelligence and language proficiency. He suggested that there is a global or general language proficiency factor which is strongly related to intellectual skills (Oller \& Perkins, 1978). Initially, he divided language use into two aspects: factive, which codes cognitive information, and emotive, which codes affective information (Oller, 1979). Within the discussion of factive language usage the term "pragmatic expectancy grammar" was introduced. This refers to the ability to partially predict what comes next in "any given sequence of elements independent of the level of language or mode of processing in the normal use of language"(Oller, 1979, p. 25). He further stated that in the meaningful use of language this expectancy must function. The ability to predict what comes next is developed through our experiences and we learn to expect certain linguistic sequences. The more experience, the more predictability facilitates rapid processing which leads to automaticity.

One of the models for automaticity for second language acquisition suggests that there are processing mechanisms which are controlled or automatic, and there are 
categories of attention (McLaughlin, Rossman, \& McLeod, 1983). In this model controlled processes have limited capacity and are temporary, whereas automatic processes are restructured units of language which no longer require focused attention to accomplish. In another model the distinction in second language learning is between explicit and implicit linguistic knowledge (Bialystock, 1978). Explicit language is the information about language that a person knows. Implicit knowledge is the language information that is spontaneously and automatically used to accomplish language tasks.

Being able to communicate in a second language requires automaticity in both the factive and emotive areas as proposed by Oller. Automaticity of cognitive information is a different demand for an individual than automatic processing of affective information. These ideas of factive and emotive aspects of language use contribute to the development of definitions and understandings of academic language and social language since they introduce a different dichotomous relationship in language use. Instead of looking at language as being divided by orality or literacy, it highlights the importance of cognitive demands of the text, whether it be oral or written.

Halliday (1978) in Language as Social Semiotic put forth the idea that language can be seen as behavior or as knowledge.
... it is possible to embed one perspective inside the other: to treat language behavior as if it were an aspect of our knowledge of language.... and also, though in a rather different sense, to treat the individual's knowledge of language as a form of behavior. In other words we can look at social facts from a biological point of view, or at biological facts from a social point of view. (Halliday, 1978, p. 13)

He outlines a perspective on language that focuses on function, on how the speaker uses language to establish, develop, or maintain social relationships. The difference between 
the child and adult world is one of abstraction. Language uses become more symbolic and represented in a more systematic and bounded structure as the child matures.

The dichotomy of language as behavior that is linked to social relationships, or language as knowledge and its symbolic representations, draws on situational context, be it person, action, or event. Language learning gradually develops and can be used free from the immediate environment. Language as behavior depends more on the specific context. It is more dependent on using language as a way to negotiate within and through the specific context, whether it be a request for attention or seeking information that relates to that behavior. On the other hand, language as knowledge is further removed and more abstract. It is confined to more specific realms of use. The varying contexts affect language use. As the "linguistic landscape" changes, the type of language used to traverse it does also. In a child's development of language this becomes increasingly important. By the time children are of school age they should understand that language is a means of learning and meanings are negotiated through its various uses and the context of the situations in which it is used. Halliday suggested that " $A l l$ language functions in contexts of situation, and is relatable to those contexts" (1978 p. 32). He proposed that the emphasis should not be on grammar, pronunciation or vocabulary in a situation, but instead the factor within the situation that allows one to predict the type of language which will occur. What information is needed about the social context that allows us to make predictions about the language is the theoretical question he asks.

This question is central to academic language development since it requires that we take the context of the situation into consideration and look more closely at the language used to function in those specific contexts. Like Oller's (1979) 
conceptualization, being familiar with the context sets up certain expectations of language, allowing the learner to make certain predictions leading to understanding. Halliday (1978) also states that familiarity with specific contexts facilitates predictions about language and its use. For example, reading expository text that compares and contrasts places different requirements on the learner in terms of linguistic knowledge, expectations and predictions, than a classroom discussion about school behavior and discipline. The former requires the knowledge of language whereas the latter relies more on the immediate environment for understanding and meaning.

Context plays a major role in the conceptualization of academic and social language through the theoretical framework of Cummins (1979). He has proposed two more dichotomies. Looking at the work of Oller (1979), he postulated that there is not a single factor global language proficiency that accounts for the variance in language proficiency. Instead, there is "cognitive academic language proficiency" (CALP) which is related to the cognitive and academic skills and also "basic interpersonal communicative skills" (BICS) which are the skills everyone uses regardless of intelligence or academic aptitude (Cummins, 1979). Furthermore, Cummins argues that there are clear differences in acquisition and developmental patterns between the two. BICS in native language is usually developed in the first six years or so. Much like the acquisition of certain functions in Halliday's taxonomy, children acquire language skills that allow them to negotiate with others in concrete ways, but have not yet made the transition to more abstract thought and more decontextualized language by the time they enter school. This is not to say basic interpersonal communicative skills are fully acquired, but that further development occurs at a much reduced level in comparison to 
initial development. However, CALP continues to develop throughout our lives (Cummins, 2000). This developmental pattern is not just for native English language speakers, but also for children acquiring English as a second language. To avoid oversimplification of these two aspects, Cummins (1984) elaborated on his theoretical framework and discussed it along two continua.

The first continuum relates to the contextual support that is available for either expressive or receptive meaning. The terms used for this are "context-embedded" where meaning is actively negotiated from the immediate environment and is supported through a variety of situational cues, and "context-reduced," where meaning is extrapolated primarily from linguistic cues or from the knowledge of language itself. Generally speaking context- embedded language is more representative of everyday type encounters, whereas context-reduced is more representative of the classroom experience.

The other continuum Cummins suggests intersects with the first one. It consists of activities and tasks of varying cognitive demand. At one end are the tasks that have become automatized and require less active involvement cognitively. At the other end are the tasks that involve more engagement cognitively, those that we lack expectations for and thus cannot assuredly predict meaning or understanding. Cummins proposes that proficiency must be thought of using both continua, not just the one that represents BICS and CALP.

These two particular terms, BICS and CALP, have come into general use in the lexicon of second language acquisition. One might even argue that they have almost reached "pop culture" status. Quite possibly the concepts of social and academic 
language for some may not have developed or moved beyond the buzz words or a simplistic rendering of these very different dimensions of language proficiency.

Nevertheless, now that there is a reconceptualization of language proficiency a major leap from the original designation of LESA has been made. The focus on oral skills and the more observable indicators of fluency are no longer the sole indicators of proficiency in a language. This is an important turning point. Not only is there a broadening in the definition, but also recognition that within that reconceptualization there are many layers.

By dividing language into dimensions of social and academic language, it must also be considered that within those dimensions there are elements that articulate between the two. There are task demands and situational contexts that affect input and output in the receptive and expressive domains, respectively. These impact directly on the user's ability to communicate competently. These two dimensions are interdependent on one another. The problem of defining the specific parameters of social and academic language encompassed in language proficiency is not as important as recognizing that there are indeed two dimensions and both social and academic language are developed for communicative competence, but academic language is necessary for success in school. As McGroarty (1984) aptly stated in her discussion of communicative competence,

Whether this kind of language is called 'text'(Olson, 1977)... 'disembedded' (Donaldson, 1978)... or cognitive/academic language proficiency'(Cummins, 1979a)... the ability to use it is a major goal in the process of schooling. (McGroaty, 1984, p. 265) 
With the signing of the Goals 2000: Educate America Act, the move toward standards based reform has contributed to a sharpening focus on academic achievement for all students, inclusive of students who are limited English proficient (Goals 2000). However, there is a continuing lower rate of high school completion for Latinos against the designated national goal of 90 percent graduation rate. Nearly $44 \%$ of Latino 16 to 24 year old immigrants drop out. Of those Latinos who are United States born about $21 \%$ drop out (Creating the Will, 2000). In light of these statistics, the development of academic language proficiency warrants significant attention in the discussion of ultimate academic achievement.

There is no one description of an LEP student. How quickly and how fully proficient each student becomes in English is dependent on countless variables. The most apparent factor is the student's literacy skills in the first language (L1). However, the length of time in the United States, the age of arrival, the length of residence, socioeconomic status, the educational background of parents, and the particular model of instruction or exposure to English are all important variables (Hakuta, Butler \& Witt, 2000) for a students' rate of acquisition and level of proficiency. Since almost half of LEP children attend schools that have at least $30 \%$ LEP populations, and immigrant children tend to live in neighborhoods where they are segregated from the mainstream economically, ethnically, and linguistically, the acquisition of academic language proficiency is a tremendous challenge. Exacerbating this situation is the lack of language development instruction at the secondary level where less than half of LEP 
students receive this specific form of instruction (Ruiz-de-Velasco, Fix, \& Chu Clewell, 2000).

It has been previously estimated that although social or basic interpersonal communicative skills can be acquired in about two or three years, more decontextualized or academic language may take from six to nine years for students to acquire the language proficiency at parity with their native English language peers (TESOL, 1999). Some estimate that full proficiency in the academic uses of English may possibly take as much as 10 years to acquire (Mitchell, Destino \& Karam, 1997). The reality is that many LEP students will have been placed in mainstream classes long before they reach this level of proficiency (Harklau, 1994).

For the last several years the growth rate for LEP students has exceeded that of the mainstream. LEP students now represent approximately one in every eleven students in grades kindergarten through grade 12 (DiCerbo, 2000). An estimated 12\% of LEP students in middle school and $20 \%$ in high school have at least two years of interrupted schooling since the age of six, and $23 \%$ have limited skills in their native language. (TESOL, 1999) As students advance to higher grade levels it is imperative they have the skills necessary to comprehend and communicate in more decontextualized learning situations. The foregoing statistics indicate a need for an increased emphasis on the importance of developing academic language proficiency which should lead to higher academic achievement for language minority populations. Increased expectations on standardized assessments stirs debate on how to include and also how to accommodate LEP students. Not to include them creates a situation where there is no accountability for 
their progress (August, 1994). Learning outcomes for LEP students has now garnered more focus.

TESOL, the international organization for teachers of English for speakers of other languages, has developed standards for grades PreK to 12 in an effort to ensure equity and opportunity in education for all LEP students (Menken \& Holmes, 2000). Their standards set goals that focus on the elements of English language, both social and academic, that students must possess in order to be successful. Many states have adapted standards for their LEP students that are either based or partially aligned with TESOL's standards.

The state of Florida references the goals and standards in its state document and also uses the definitions of English language proficiency levels (Short, 2000). The three goals as designated for the TESOL standards, varying in specificity by grade levels, are for students to develop competence in social language, academic language, and sociocultural knowledge in English (TESOL, 1997). To be able to use English to accomplish academic tasks and to foster academic learning is tantamount to achievement at the secondary level. The development of English for social purposes is to further communicative competence in interactions. Learning to understand and express basic desires and needs is on one end of a language continuum, whereas talking to learn new concepts, gather information, reflect on abstract theories or ideas, is much further along the continuum and requires a different type of discourse (Westby, 1985). Since ultimately, students need to be able to learn concepts as well as language, using content at grade level provides students with authentic purposes for using and developing language. The integration of content and language has been a movement in the field for about the 
last fifteen years with the rationale being that students can more readily acquire academic language when language development is intertwined with content acquisition (Gersten, 1999). This was a driving force behind the development of the Cognitive Academic Language Learning Approach (CALLA) by Chamot and O'Malley (1987). They proposed that intermediate and advanced level LEP students transitioning to mainstream content area classes need to develop learning strategies and English language skills related to academic areas. Sheltered instruction, another instructional model that is grade level instruction in a content area, specifically designed for LEP students with a language development approach. It can be taught by an ESL teacher or a content area teacher with special training. At the high school level it is more often delivered by the content area teacher because of credit issues (Short, 2000).

By integrating content and language students learn the discourse necessary to succeed in the content areas at grade level and ultimately with grade level peers who are not LEP. This promotes development of academic language through more cognitively demanding tasks moving along the two continua proposed by Cummins (1984). As previously discussed, as language proficiency develops and tasks increase in cognitive demand, language skills become more automatic. Abstract or decontextualized concepts become more accessible. But how do teachers do this? What instructional strategies are the most effective in providing opportunities for this development of academic language proficiency?

\section{Instructional Strategies}

This researcher in various teacher training contexts, has often heard the remark that strategies for LEP students are just "good" ways of teaching and are nothing 
different. That statement is only partially accurate because instructional strategies for LEP students include strategies for general instruction as well as for language development. General instructional strategies include the following: organization of instruction in thematic units or in a predictable manner; engagement of learners in instructional tasks which develop comprehension and higher order thinking; integration of students' background knowledge and personal experiences to current learning; and orientation of activities balanced between teacher directed, small cooperative groups, and individual (Fradd \& McGee, 1994).

Instructional strategies for second language acquisition focus on making communication authentic, interactive and purposeful. Depending on the learners' characteristics and needs, strategies for language development for LEP students may include: use of context clues and concrete referents, such as graphic organizers and visuals; modification of language including paraphrasing, repetition, clarification requests; integration of literacy and language through recognized approaches such as Total Physical Response (Asher, 1982), the Natural Approach (Krashen \& Terrell, 1983), Whole Language Approach (Goodman, Goodman \& Hood, 1989) and the Language Experience Approach (Dixon \& Nessel, 1983).

An extensive qualitative multivocal research synthesis undertaken by Gersten and Baker (2000) attempted to answer the question: What do we know about effective teaching practices for elementary and middle school LEP students? Their analysis looked at current problems while also trying to identify specific strategies that promote Englishlanguage development in academic instruction. They identified five instructional strategies that may be critical for instruction of LEP students: "(a) building and using 
vocabulary as a curricular anchor, (b) using visuals to reinforce concepts and vocabulary, (c) implementing cooperative learning and peer-tutoring, (d) using native language strategically, and (e) modulating cognitive and language demands" (p. 462 ).

Gersten and Baker (2000) discussed the reasons for the usage of these particular strategies. Vocabulary is key to being successful in the academic sphere. However, with LEP students vocabulary should be limited to under seven words and be chosen to provide students with the most cogent concepts. Additionally, it is recommended that vocabulary be taught explicitly and prior to encountering it in written text. Visuals are of extreme importance to LEP students since they are a way to contextualize concepts. They make abstractions more tangible. This strategy ranges from providing students with graphic organizers to just writing key words and discussing them. In order to further understanding of content material, students need to be given the opportunity to interact with others. Working with a peer on a task of being part of a cooperative group which is collaborating on a larger task provides students with interactions which support their learning. Use of native language has viability in the classroom since it provides students with understanding more cognitively demanding concepts or decontextualized language. However, there is debate on when and how to use native language. Simultaneous translations are ill advised. Nevertheless using linguistic support in the students' native language dissolves the barrier to understanding and makes comprehension of abstract concepts more likely. The last strategy discussed is that of modulation. This requires the teacher to adjust cognitive demands with language demands. It is proposed that when tasks are very cognitively demanding that every effort be made to balance that by language which does not make excessive demands on the learner for understanding. 
Conversely, when the task is not particularly demanding then language can be scaled to a higher level. This allows LEP students to articulate between as well as move along the two continua of task demand and context embedded or decontextualized language.

One of the major observations made by Gersten and Baker (2000) had to do with the use of natural language. They stated that there appears to be too much emphasis on oral natural language to the detriment of developing concepts or accessing academic content. Sole use of conversational, embedded or social language does not provide students with a variety of linguistic and cognitive experiences and language skill development.

This brings the discussion back to the areas of social and academic language. How do teachers differentiate between the two and how are tasks structured to promote higher level thinking? If it is only context that differentiates social from the academic, then is embedded language in school social or academic? Do tasks which are less demanding promote social language or do they promote academic language? It is possible that students may not develop academic language due to the language skill they use to discuss concepts. It is also possible that language skills might limit the access to content, therefore, students only get the "big picture" and have difficulty moving from frame to frame to the eventual synthesis of information. What do teachers of these students need to know and how likely are they to be able to provide effective instruction?

\section{Teachers of LEP Students}

As the population of LEP students increases the United States faces a strange convergence: more accountability and higher educational standards and a major teacher shortage. Considering the changing demographics it can be anticipated that over half of 
all teachers will be responsible for educating an LEP student at some point in their career (McKeon, 1994). Less than five years ago only about $2.5 \%$ of teachers who instruct LEP students held degrees in English as a second language or bilingual education. Only about $30 \%$ of all teachers with LEP students had received any professional development for instructing this particular population (National Center for Educational Statistics, 1996).

A disparity exists between what these students need for language and content knowledge development and the dearth of teachers who have the knowledge and expertise to deliver it. Additionally, with a sizable portion of LEP students living in high poverty neighborhoods, their chance of having teachers who are certified in the same content area they are teaching dwindles. As an example, approximately $71 \%$ of secondary school students taking science subjects in high poverty districts were being taught by teachers who had neither major, nor minor in the field of science. As in many subject areas, the number of qualified, certified ESL teachers is also at a premium. More than one fifth of states do not require ESL or bilingual education certification or endorsement. (McKnight \& Atunez, 1999). At the secondary level many of the content area teachers believe that developing students' literacy skills or development of academic language skills is not part of their responsibility (Ruiz-de-Velasco, Fix, \& Chu Clewell, 2000). Besides lacking expertise or a specific content knowledge base there is also a disparity between the student population and the teacher population.

Researchers have argued that there is a link between language and culture (Heath, 1983). They have suggested that acquiring a second language facilitates the acquisition of a new perspective of the world (Freeman, 1994). LEP students bring with them a different culture and language. Teachers who instruct them need to be aware of the 
interactional styles of various cultural groups that may be in conflict with their own.

Teachers' perceptions help determine the way they instruct, organize their instruction, and adjust their expectations. However, certain disciplines such as language arts or science may require particular discourses which may or may not be congruent with a student's own culture. Researchers have noted that students' styles of interaction may lead to lessened participation in a classroom or even ineffective participation (Lee \& Fradd, 1996). The shrinking pool of teachers who are able to teach linguistically diverse students creates a greater need for professional development and teacher education programs. What is the knowledge that teachers, particularly those responsible for language skill development, need to have?

\section{Teacher Knowledge and Practice}

There is an underlying perception from other content area teachers that ESOL teachers are able to prepare LEP students for all English classes in a short time and have sole responsibility for teaching them English (Constantino, 1994). Although this may be a misconception, ESOL teachers do need to have to special knowledge beyond a content or subject area.

A study by Constantino (1994) compared and contrasted the knowledge of secondary all-English teachers and ESL teachers. She specifically looked at their knowledge of second language acquisition and pedagogical adjustment, language and content integration and parental involvement in the schooling process. Fradd and Lee (1998), in a description of a teacher education program, described three domains which created a TESOL knowledge base: knowledge of ESOL academic content, knowledge of the specialized pedagogy, and knowledge of community. In both of these descriptions 
there are commonalties. A knowledge of language acquisition, academic content area and culture provide teachers with an understanding of how language is acquired and how linguistic, sociological and psychological perspectives factor into the acquisition process and how that articulates with language instruction. Because of differences in literacy and educational backgrounds of LEP students, creating meaningful instruction means having an understanding of curriculum adaptation and methods and strategies for instruction that is comprehensible and addresses students' cognitive and linguistic demands (Fradd \& Lee, 1998). In addition, being an ESOL educator usually places a teacher in the position of liaison and advocate within the school community. Knowledge of policy and practices allows teachers to facilitate parents and colleagues' understanding of the issues and needs of this particular population.

In the state of Florida ESOL teachers are required to be ESOL endorsed. Besides having certification in another subject area, they must also have a passing score on the Test of Spoken English and fifteen semester hours in English to Speakers of Other Languages which must include credit in five specific areas: methods of teaching English to speakers of other languages; ESOL curriculum and materials development; crosscultural communication and understanding; applied linguistics; and testing and evaluation of ESOL (LULAC v. Department of Education, et al Consent Decree, 1990). Moreover, the Office of Multicultural Student Language Education through the Florida Department of Education has specific performance standards for teachers of English for speakers of other languages. The primary focus of this office is to monitor school districts for compliance with the Consent Decree, and assist schools in providing comprehensible instruction to LEP students. Expectations of what these teachers must know and be able 
to do are clearly delineated. Specific to social and academic language development and strategy use are the following:

Determine and use appropriate instructional methods and strategies for individuals and groups, using knowledge of first and second language acquisition processes

Apply current and effective ESOL teaching methodologies in planning and delivering instruction to LEP students

Select and develop appropriate ESOL content according to student levels of proficiency in listening, speaking, reading, and writing, taking into account: (1) basic interpersonal communicative skills (BICS) and (2) cognitive academic language proficiency skills (CALPS) as they apply to the ESOL curriculum

Apply essential strategies for developing and integrating the four language skills of listening composition, oral communication, reading, and writing Evaluate, design and employ instructional methods and techniques appropriate to learners' socialization and communication needs, based on knowledge of language as a social phenomenon (OMSLE, 2000).

What teachers know and what they believe affect their interactions with students and instructional decisions. Of tantamount importance to effective instruction is the congruence between instructional intent, organization and delivery of instruction, and expected student outcomes (Tikunoff, 1987). In order to produce desired student outcomes, there must be effective instruction. The teacher's intent of student learning outcomes, the organization of instruction to meet the intended outcomes, delivery of that intent, and what the students actually accomplish must all be aligned. However, there may be disparity between what teachers know and what they actually do in the instructional context.

In Constantino's (1994) study though teachers had articulated a common belief system, what they actually did in their classrooms belied their practice. Most of the teachers had stated that making content comprehensible and providing plenty of opportunity for negotiated exchanges were needed for language acquisition and 
development. In their description of classroom activities no evidence was provided to support adjustment or modulation of discourse or social and physical arrangements of the class. Lesson plans did not reveal changes in content organization to facilitate exchanges.

In articulating how one behaves under certain circumstances people usually give their espoused theory of action. That is to say that they explain what they would do in a certain situation if they wished to achieve certain consequences given prescribed assumptions. Theories of action that are interrelated and act in sequence to elicit a desired outcome are known collectively as a theory of practice. However, frequently, the theories in use, in other words, the actual behavior in a particular situation, are contrary or not congruent with what has been communicated or stated previously as the espoused theory (Argyis \& Schon, 1974). More often than not, the individual is not aware of the incompatibility of these two theories.

In Constantino's (1994) study the teachers' espoused theories, those that they were able to articulate or communicate with others, were not congruent with their theories of practice, the theories they used to govern their actions. The behaviors that they demonstrated and were observable were not compatible with what they had stated they believed.

The knowledge that teachers acquire as they broaden their knowledge base and gain experientially, develops into the teachers' implicit theories which drive their instruction. What teachers know about social and academic language and how extensive a knowledge base in content and second language acquisition they possess are important to their theories of action as are the instructional strategies they employ to bring about 
specific consequences of learning. How they are able to operationalize that knowledge and those beliefs are observable through their theories of use and their artifacts. The development of a knowledge base for secondary school teachers is primary, but ultimately, the effectiveness of instruction, the congruence of intent, delivery, and outcome; and the compatibility of teachers' theories of practice and theories of use are most critical to LEP student success in the classroom.

Summary

This review of literature explained different conceptualizations of social and academic language. Additionally recent information on instructional strategies for LEP students was discussed. Final focus was on teachers' knowledge, professional preparation, and practice. 
CHAPTER III

\section{RESEARCH METHODOLOGY}

This third chapter discusses the methodology used in this particular study. The collection and interpretation incorporated both quantitative and qualitative methods. It is a mixed method study (Tashakkori \& Teddlie, 1998). This type of methodology was chosen to provide a more integrated approach to examining what secondary ESOL teachers know about social and academic language and how they operationalize that knowledge in the classroom. It was decided that data should be collected in three phases. The first phase using a written questionnaire collected both quantitative and qualitative data. The second phase, the interview phase, gathered qualitative data for further elaboration of teachers on the questionnaire. The final phase collected data that elaborated on the information from the interviews.

\section{Description of Methodology}

It was determined that a questionnaire would be an appropriate vehicle to ascertain information from teachers on their conceptualizations and categorizations of social and academic language, as well as providing their choices of instructional strategies and frequency of usage. The quantitative data was collected first with the intent that it would lay a preliminary foundation to the collection and interpretation of the qualitative data and provide one point of view of these constructs.

Data collected from questionnaires are used to determine the current status of a population with respect to certain variables (Gay, 1996). Closed ended questions alone would not have provided an opportunity for the researcher to understand the perspective 
of the responders on their conceptualization of social and academic language (Patton, 1990). Yet open-ended questions allow responders to give more detail. Nevertheless, even these responses are limited since effort and extended time are required from those who are being surveyed. Additionally, there is not an opportunity to elicit extended responses or probe for additional information. Therefore, it was decided that interviewing was a viable addition to the data gathering process. An open-ended interview was used to provide more systematic responses. It was also used to facilitate cross-case analysis.

The quantitative data focuses on the frequency and type of instructional strategies and teachers' educational backgrounds, class configuration and/or proficiency levels of students, and native languages. Other quantitative data looks at the responders and their categorization and definition of social and academic language. Qualitative data further examines teachers' definitions and perceptions of social and academic language, their descriptions of instruction and the congruence between their espoused theories of action with regard to instructional strategies and academic language development and theories of use in terms of their operationalizing these concepts in classroom instruction (Argyis \& Schon, 1974).

In order to meet the needs of the range of data, this study consisted of three different phases in data collection: a written questionnaire, one to one interviews, and classroom observations. The questionnaires were used to gather basic demographic information and assess instructional strategy use, social and academic language example categorization and definitions. Interviews were conducted to further elaboration on teachers' definitions and conceptualizations of social and academic language, as well as 
obtain descriptions of teachers' instructions and the operationalization of their descriptions of in an instructional setting. Observations were made to determine actual instructional use and academic language development within the individual classrooms.

More validity and credibility can be realized in a study of this type with triangulation (Patton, 1990). Data sources were triangulated since interview data was compared with observational data. Methods were triangulated through the use of both an interview and a written questionnaire on definitions and categorizations of social and academic language and on strategy usage.

\section{Research Context}

The research activities for this study covered a six-month period from April 2001 through October 2001. Data was gathered from secondary schools throughout the entire Miami-Dade County Public School District. There are a total of 53 middle schools, 33 high schools, and 15 alternative education sites at the secondary level in the district which is divided into six regions.

The district reported a rate of $54 \%$ for current or former LEP students within their total student population in 2000 . The overall secondary population of LEP students for the academic school year of 2000 to 2001 was approximately 20,000 students, a percentage that is slightly less than one third of the entire LEP population.

At $86 \%$, Spanish is the predominant language represented by LEP students in this district, and the Haitian-Creole population of LEP students is second at 11\%. The remaining LEP population is stippled with other languages, the most frequent being French, Portuguese, Zhongwen, Urdu, Russian, Arabic, Tagalog, and Vietnamese (Miami 
Dade County Public Schools Division of Bilingual Education and World Languages, 2001).

\section{Participants}

The participants in the study were ESOL teachers at the secondary school level that includes middle and high school teachers. When the study began there were 311 teachers assigned by the district as full time ESOL teachers. Teachers are assigned to teach the English or Language Arts through ESOL, a content integrated course, or the ESOL reading and writing elective, or a combination of the two: In the instance of the former course, students are grouped by grade since the material is at grade level. The latter grouping is based on students' English oral language proficiency and they are placed according to levels that range from the lowest of one, to the highest level for program participation, level four. Teachers who are assigned to instruct in these courses must have an ESOL endorsement or certification. The teachers contacted represented those who had full time teaching assignments. Teachers who had a supplement and only taught one or two classes were not represented in this study. Participation in this study was purely voluntary.

\section{Procedure}

A questionnaire (see Appendix A) was created by the researcher to elicit responses to questions posed in the study. The first four questions gathered information on teachers' experience in teaching ESOL, their educational background, and their native language. A fifth question dealt with how their classes were grouped. The next four questions, which were multiple choice, concentrated on definitions of social and academic language. These were followed by open-ended questions. Three of these asked 
for examples of each type of language as well as an explanation of how to differentiate between the two. A fourth question asked the respondents to explain how they would instruct students of various proficiency levels for academic language development. Next a section was included that asked participants to classify various examples as academic or social language. Finally, a list of instructional strategies was given for respondents to designate their individual use and frequency of use in a one-month period. Progress indicators from ESL Standards for Pre-K-12 Students (TESOL, 1997) were used as a basis to frame examples and definitions of social and academic language for content validity.

A pilot questionnaire was given to five teachers in order to determine whether or not there were problems in interpreting questions and in order to get an approximate estimation of time involved in responding to the questionnaire. A concern of the researcher was the feasibility of the study. Four of the teachers in the pilot were middle school teachers assigned to a full ESOL teaching schedule: one with a master's degree in TESOL, one who was beginning an urban education and TESOL master's program, one with a bachelors degree and K-12 ESOL certification, one with elementary education certification and ESOL endorsement, and the fifth was a supervisor from the district office with elementary and high school teaching experience. After completion of the questionnaire the responders were all informally interviewed and asked to offer comments on the organization and presentation of the questionnaire and the framing of various questions. Their comments and observations resulted in a few minor changes to the questionnaire. The formatting was changed to a more readable and less crowded 
questionnaire. It became a three page questionnaire and the strategies for selection were placed after the open-ended questions rather than before.

Since there is a period during which schools are preparing students for standardized state testing and administering of these tests, questionnaires were sent out after the third grading period had ended. This allowed sufficient time for ESOL teachers to respond prior to their being involved in district end of year testing for individualized oral language proficiency assessment of all LEP students and program documentation and end of the year examinations.

Questionnaires were mailed via United States mail to every secondary teacher identified in the district at the school sites. The actual number of questionnaires mailed was 306 since the other five teachers were excluded due to pilot study participation. Included in the questionnaire packet were the following: a letter from the chairman of the research review committee of Miami Dade County Public Schools (Appendix B); a letter from the researcher (Appendix C); the three page questionnaire; a postage return envelope; and a postcard that verified the return posting of the questionnaire and an indication of the willingness of the teacher to be interviewed at a later date. Two weeks after the initial posting of questionnaires, the researcher began making contact with teachers asking them to return questionnaires if they had not yet done so. This contact was done by phone as well as by fax. Questionnaires were returned over a two-month period. Contacts for interview times were begun just as the school year ended. The interviewing process was begun about two weeks after the end of the school year. With the exception of one interview, all were done on the phone. 
Open-ended questions were selected from the questionnaire and reframed to gather definitions and explore strategy use. This specific protocol, (Appendix D), was consistently used, but in later interviews more informal and spontaneous probing questions were also asked of interviewees. At the conclusion of each of the interview sessions teachers were asked about their willingness to be observed. All of those interviewed gave consent for later observations, however most of them indicated that they would not be in the classroom during the summer session and would have to be observed several weeks after the new school year began. From these teachers, ten were selected for observation.

Even though there were higher response rates from certain regions, the researcher made every attempt to have representation from all regions in the district, to have an equal balance between middle and high school, to have teachers of different genders, ethnicities, and linguistic backgrounds, and to observe English/Language Arts Through ESOL and ESOL reading and writing elective classes. Since nearly two and a half months passed since the initial contact with the mailed questionnaire, by the time autumn began and the new school resumed some teachers had been reassigned to other subject areas, others no longer showed interest in the interview and did not return calls, so teachers were selected on availability within the designated timeline.

After receiving consent from the individual teachers and setting a specific observation time, school principals or assistant principals were contacted to gain permission to be at school sites. Some schools required documentation from the researcher before admittance to classrooms, whereas others only needed the researcher to sign in and out with the main office. Observations varied in time due to block scheduling, 
special presentations, or classroom activities. The minimum time of any observation was 50 minutes. Several observations were for two or more hours because of block scheduling. Although, the intention of the researcher was to be a non-participant observer, in three instances either students or teachers tried to actively engage the researcher in the classroom activities.

All taped interviews were transcribed for coding and all observations were written from original field notes. Observations of teachers focused specifically on instructional strategies and academic language development. The observations were paired with the transcriptions of the interviews to look for congruence between teachers' descriptions of instruction and actual instruction as observed. Additionally, the instructional strategy use reported by teachers and the instructional strategies used by those same teachers were compared.

\section{Analysis and Coding}

Analysis and coding methods evolved as the study was in process. For the questionnaire, descriptive statistics were used to provide information and Chi square inferential statistics were used for comparison of groups for strategy use. For the openended questions, interviews, and observations, coding followed strategies articulated by Miles and Huberman (1994). The creation of visual displays was part of the analysis process. By using a matrix, moving between the actual data and the potential categories, meaningful patterns can be recognized. Two separate checklist matrices were developed: one for definition and examples of social and academic language, and the other for description of instruction for academic language for beginner, intermediate, advanced and multilevel classes. The researcher compared teacher's descriptions of 
their instruction and their strategy use in the transcriptions of their individual interviews, matching them with their actual instructional practice as observed.

\section{Summary}

This chapter presented the procedures and methods used in this study.

Quantitative and qualitative methods of collection and interpretation were chosen to provide a more integrated approach in examining the questions. The presentation, analyses, and interpretation of the data follow in the next chapter. 


\section{CHAPTER IV}

\section{FINDINGS}

Teachers' definitions of social and academic language were of primary importance in this study. Their conceptualizations of social and academic language and their descriptions of their instruction were examined. Information on the types of instructional strategies they use, their reported frequency of instructional strategies, and choice of strategies for varying English proficiency levels was collected for examination.

Responses from teachers were drawn from questionnaires and interviews, and information on the operationalization of their definitions was gathered through classroom observations. The researcher made every attempt to obtain participation from all full time secondary ESOL teachers in the district. The participants in this study represented all regions in the Miami-Dade County Public School District, but in varying percentages. The specific breakdowns per region for each phase of the study are included in Table 1. Questionnaires were anonymous, but teachers confirmed their participation through a separately mailed postcard. The data for questionnaires in Table 1 reflects the 83 teachers who confirmed their participation.

\section{Demographic Description}

All regions had a minimum participation for written questionnaires of $13 \%$. For interviews only Region II and IV had less than 10\% participation. Region II was the only region without representation in classroom observations within the study. There was a period of approximately two months between the completion of the questionnaire and follow up interview and another two months or more before classroom observations. 
Some teachers were reassigned to other school sites or no longer wished to participate when contacted, therefore teachers for classroom observations were selected on availability and with attention to the timeline for the data collection.

Table 1

Teacher Participation in Questionnaire, Interview, and Observation by Region

\begin{tabular}{lcccccc}
\hline Region & $\begin{array}{c}\text { Questionnaire } \\
\%\end{array}$ & $n$ & $\begin{array}{c}\text { Interview } \\
\%\end{array}$ & $n$ & $\begin{array}{c}\text { Observation } \\
\%\end{array}$ & $n$ \\
\hline Region I & 25.30 & 21 & 17.39 & 4 & 20.00 & 2 \\
Region II & 13.25 & 11 & 8.70 & 2 & 0.00 & 0 \\
Region III & 16.87 & 14 & 17.39 & 4 & 10.00 & 1 \\
Region IV & 15.67 & 13 & 8.70 & 2 & 10.00 & 1 \\
Region V & 14.45 & 12 & 21.74 & 5 & 20.00 & 2 \\
Region VI & 13.25 & 11 & 26.09 & 6 & 40.00 & 4 \\
$\quad$ & & 83 & & 23 & & 10 \\
\hline Total & & & & & & \\
\hline
\end{tabular}

Since one of the questions focused on differentiation of strategy use, data was gathered on teachers' experience in teaching ESOL, native language background, and method of endorsement or certification. Experience ranged from first year teachers to 30 year veterans in the field of teaching English to speakers of other languages. The majority of teachers who responded to the questionnaire had a minimum of four years teaching in the field (see Table 2). 
Table 2

Teachers' Years of Experience

in Teaching ESOL $(N=87)$

\begin{tabular}{lcr}
\hline Years & $\%$ & $n$ \\
\hline $1-3$ & 19.54 & 17 \\
$4-11$ & 36.78 & 32 \\
$12-19$ & 24.14 & 21 \\
$20-30$ & 16.09 & 14 \\
Over 31 & 3.35 & 3 \\
\hline
\end{tabular}

Table 3

Native Language Background

of Teacher Participants $(N=87)$

Language $\quad \% \quad n$

\begin{tabular}{lll}
\hline English & 40.24 & 33
\end{tabular}

Fr./H.Creole $\quad 7.32 \quad 6$

$\begin{array}{lll}\text { Spanish } & 42.68 & 35\end{array}$

$\begin{array}{lll}\text { Sp./Eng. } & 3.66 & 3\end{array}$

$\begin{array}{lll}\text { Other } & 6.10 & 5\end{array}$

Teachers who participated in this study, represented the diverse language backgrounds that are present in Miami-Dade County. Most teachers were either native English or Spanish speakers. Some identified themselves as dual language speakers of French and Haitian Creole, or dual English and Spanish speakers. Native speakers of 
other languages included Russian, Romanian, Portuguese, Hungarian and German (see Table 3).

Teachers received their ESOL endorsement or ESOL certification in a variety of ways. For endorsement the consent decree requires the equivalent of 15 college credit hours with courses in methods of teaching English to speakers of other languages; ESOL curriculum and materials development; cross-cultural communication and understanding; applied linguistics, and testing and evaluation of ESOL. Teachers have the option of obtaining credit through TEC or college programs, or through a combination of the two. Because so much course work is involved for endorsement, some teachers opt for the master's program.

Table 4

Method of Endorsement or Certification in $\operatorname{ESOL}(N=87)$

Method $\quad \% \quad n$

\begin{tabular}{lll}
\hline College Credit & 80.46 & 70
\end{tabular}

Teacher Education Credits $\quad 13.79 \quad 12$

TEC/College Credit $\quad 5.75 \quad 4$

Grandfathering $\quad 1.15 \quad 1$

This particular population of teachers either received their endorsement or certification through Teacher Education Credits (TEC), college credit, grandfathering, or a combination of TEC and college credit. The majority, slightly more than $80 \%$, had either endorsement or certification through college credit. Of this number 65 of the 89 
teachers who responded had graduate degrees. Of those who identified their majors, 39 were in TESOL or Bilingual Education. The method teachers indicated for their certification or endorsement is in Table 4.

Triangulation uses multiple perceptions to clarify meaning (Denzin \& Lincoln, 1998). After conducting a written questionnaire on definitions of social and academic language and the use of strategies, interviews were conducted to verify these different conceptualizations and strategy use. Definitions gathered in interviews were compared with observational data to obtain a deeper understanding of teachers' conceptualizations of social and academic language and how those conceptualizations influence instruction. This section is organized in terms of the five research questions:

1. What are the criteria secondary ESOL teachers use to differentiate between social and academic language and what language examples do they identify as being characteristic of each category?

2. What instructional strategies do secondary ESOL teachers most frequently use to promote academic language with LEP students with beginning, intermediate, advanced or multiple level classes?

3. How do secondary teachers describe their instruction for promoting academic language?

4. Are teachers' descriptions of their strategy use differentiated on the basis of (a) the level of students' proficiency in English, (b) teachers' professional preparation, (c) teachers' own language background?

5. Are teachers' descriptions of the strategies they use to promote academic language proficiency congruent with their daily practice? 
The sequence of analysis reports the findings in the order of each question. The

first and second questions generated both quantitative and qualitative data. The third and fifth questions were qualitative in response, and the fourth question was comprised of quantitative data. Results are reported for both types of data and both sources for each question. Open-ended responses from questionnaires are noted in parentheses with the letter "S" and a teacher's number. For example, (S15) would refer to the response of teacher 15 from the questionnaires. Responses from interviews are noted in parentheses with the letter " $\mathrm{I}$ " and a number. Therefore, (I23) would refer to a teacher in the interview group. Since observations came from the teachers interviewed classroom teacher observations continue with the use of the letter "I " designation since they are observations that were conducted from the interviewees.

Differentiation of Social and Academic Language

Question One: What are the criteria secondary ESOL teachers use to differentiate between social and academic language and what language examples do they identify as being characteristic of each category?

\section{Questionnaires}

Open-ended questions on the questionnaires, and individual interviews provided the information for the first part of this question. Questionnaire information is presented first.

Out of the 89 questionnaires, 12 teachers did not respond to the question about differentiation between social and academic language. This is $13.48 \%$ of those surveyed. Teachers may not have responded because they were unfamiliar with the terminology, or because they had difficulty articulating differences. There were 6 teachers, or $6.74 \%$, in the written questionnaires who stated specifically a differentiation between social and 
academic language. "The differentiation is by frequency of usage and context" (S13). "It is due to the topic of conversation" (S15). "Academic language is on a higher level than social" (S26). "Structures of both are different" (S34). The most specific differentiation stated that the criteria was "by context in which communication takes place and the kind of language, level of words, structures and formality" (S57). The other 71 teachers, $79.76 \%$, gave definitions of either social or academic language or discussed various aspects of one or the other, or both, but not in a contrastive or comparative way which would delineate specific criteria for differentiation.

\section{Themes}

In examining definitions of social and academic language, themes from theory and practice emerged. Teachers' concepts ranged from focusing on morphology, syntax, and semantics, to broader ideas on how language is used and for what purposes. Teachers tended to use one of the five following categories in defining either social or academic language: content, vocabulary, form, task, or context. Content refers to subject areas such as language arts, social studies or biology. Vocabulary refers to words or terminology. Form focuses on issues of grammar. Tasks are prescribed types of work Context includes particular situations or circumstances from which meaning may or may not be derived. These will be the subheadings used to report the results from the questionnaires and interviews. Themes, along with the percentages for each category, are shown in Table 5.

Content. When used to delineate social or academic language, content was almost never used in a definition of social language. Only $1.1 \%$ of the teachers used it and couched it in terms of the subject of "everyday needs" (S31), whereas $17.97 \%$ used 
content to define for academic language. The responses ranged from general definitions to comments that connected academic language and content. These 16 teachers stated that academic language is either necessary for content knowledge or that academic language is related to specific topics. Quotations from their questionnaires articulated this concept. "It is textbook and subject area language" (S36). "It is more content specific and requires different levels of reading and writing skills" (S40). Academic language is "specialized expressions characteristic of a field, subject..."(S43).

"Academic language is content based. It is concepts and definitions" (S76). "Academic language is particular to a field of study... involves processes and concepts" (S27).

"Academic language is developed through content of different topics" (S12).

Table 5

Categorizations for Social and Academic Language

from Questionnaires $(N=89)$

\begin{tabular}{lcccr}
\hline Themes & Social\% & $n$ & Academic \% & $n$ \\
\hline Content & 1.10 & 1 & 17.97 & 16 \\
Vocabulary & 0.00 & 0 & 5.62 & 5 \\
Form & 24.72 & 22 & 22.47 & 20 \\
Task & 3.37 & 3 & 12.36 & 11 \\
Context & 46.07 & 41 & 16.85 & 15 \\
& & & & \\
\hline
\end{tabular}

When asked for specific language examples, teachers exemplified this concept by giving samples of language that were tied directly to specific content areas. Three teachers just listed subject areas such as math, literature, science, and social studies. An example 
given by one teacher suggested that the ability to explain a scientific theory demonstrating full comprehension, or defining a term such as "hypotenuse" would suffice as a demonstration of academic language.

Vocabulary. Although $5.62 \%$ of teachers mentioned vocabulary as a factor for defining academic language, no one mentioned it in defining social language. The most general definition for academic language was in stating that it was "schoolwide vocabulary." For the most part, it was discussed as " a difficult set of vocabulary" (S25) or "specific detailed vocabulary" (S31). Two teachers tied academic language directly to subject area through vocabulary usage, "stresses vocabulary of subject area" (S46). Academic language is "vocabulary, terminology, concepts in the curriculum and content areas" (S84). As noted previously, vocabulary was not a major point of delineation between academic and social language, nor even a major factor related to defining academic language.

In trying to give examples in this area, teachers listed words that students might use which they felt reflected academic language: "histrionics," "simile or metaphor," "literary genres," "Pythagorean theorem."

Form. Form was used nearly equally in definitions for social and academic language. For social language $24.72 \%$ of the teachers identified form, compared to 22.47 $\%$ for academic language. Seven teachers defined it in terms of grammatical structure only or by an emphasis on grammar rules. Academic language is "formal grammar and syntax" (S46). Eighteen teachers used the terms "informal" and "formal" to distinguish between social and academic language respectively. Five gave what became termed as "translations" of the same information stated in "social language" and the equivalent in 
"academic language." For example, "We're gonna go to the beach" became "We are going to go to the beach." Or "I ain't goin" with you" became "I am not going to go with you" (S14). "What's up?" was considered as an example of social language, which if it were said "academically" would be "How are you?" (S55). Nine teachers indicated that the difference was between slang, curse words, idiomatic expressions, or vernacular and what they termed "standard English." "Billy is da bomb" was translated to "Billy is an extraordinary young man" or "Girlfriend, you in danger, child" to "Young lady, you are in danger" (S64). The idea of being able to translate from one form to another was implied mostly through examples. One teacher stated it more directly by saying, "My dentist uses a foreign language when speaking to her assistant, "bicuspids"...My mechanic when translating my funny sound to fixable terms" (S79). Still another remarked that an example of social language use is "when a student doesn't understand and asks me to translate into everyday language... to use the language they understand" (S54). It appears that five teachers consider social and academic language as two distinct "languages" as opposed to aspects or dimensions of language.

Task. Only three teachers, $3.37 \%$, discussed task in their definitions of social language, whereas 11 , or $12.36 \%$, related academic language to some task. Although task was not used in defining academic language it was often used for examples of academic language. The list of tasks was extensive and varied: "to ask and answer questions for topical discussions," "to read passages," "to think about and explain informational text," "to compare and contrast information," "to explain language structures," "to give details from stories," "to retell a narrative," "to give a speech," "to takes notes from a lecture," "to write an essay," "to role play an interview," "to analyze 
stories or arguments," "to debate topics," to evaluate experiments," "to research topics," "to locate information," "to give definitions," "to read directions," "to state an author's purpose," "to work in cooperative groups." What seemed to be the rationale behind the preponderance of tasks as examples of academic language was summed up by two teachers. One commented, "Academic language is needed for learning" (S42) and another similarly remarked, "Academic language is the one used for learning" (S68).

Context. The highest indicator used in the definition for social language was context. It was mentioned by $46.07 \%$ of teachers which contrasted markedly with context as a factor in defining academic language at $16.85 \%$. An example of how a teacher used context for academic language was, "Academic language is less context embedded" (S89). However, social language was defined through context by setting or situation. One teacher stated that "social language fulfills basic interactional functions of language, that is to set up social relationships" (S85). Another responded that social language is "language which students acquire by interacting with peers and through the media" (S80).

Whereas in the defining of academic language multiple examples of tasks were used for explanation, a variety of student interactions were listed as examples of social language: "speaking to each other about homework," "writing letters," "discussing weekend plans," "working cooperatively," "asking for a sale item," "giving an opinion about a school event," "answering questions about personal likes and dislikes," "talking on the phone," "making personal connections to material," "expressing needs," and "discussing general topics". Synonyms given by three teachers for social language were "conversational language," "kitchen language," and "playground language." Four others 
stated that social language could not occur in school or in an academic context.

However, another teacher observed that "social language enables individuals to ask and respond to information needed in day to day living... in and out of the classroom" (S74).

Overall, teachers who chose to define social language using context saw an interactive component as part of social language development.

Other comments, which arose from the open-ended questionnaire questions, addressed teachers' ideas on second language acquisition. One teacher saw academic language as a sequential progression from social language, "Social language is used first and assists in academic language acquisition" (S40). Moreover, four indirectly stated social language was acquired, but 11 commented that academic language was learned. "Academic language needs to be taught" (S25). "Academic language is the one you need to get or give instruction for, to acquire knowledge" (S75). This would relate to previous teachers' comments linking academic language as the language needed for learning and suggesting that is the reason it needs to be taught.

Overall, in the questionnaires, teachers used content, form, and context as categories in their definitions more often than either vocabulary or task; context was used more frequently for social language definitions, whereas content was more often indicated as a factor in defining academic language. Eight teachers saw language as touching on various areas and blended content and context, or context and task.

\section{Interviews}

The data from the oral interviews ran parallel to the data collected from the open ended questions on the questionnaire. Interviewed teachers' remarks were extensions of comments made on the written questionnaires and fell into the same categories for 
discussion. The 23 teachers who were interviewed had already participated in the written questionnaire and those particular responses remained anonymous. However, these teachers were asked similar questions from the written questionnaire to elicit more complete explanations. During the interviews teachers attempted to clarify their view of language. Nine teachers verbalized an interelatedness of social and academic language. One teacher stated it in this way, "I'm always in and out of social and academic language... once they really have the academic it can be used in a social context" (I23). Another teacher remarked that, "academic and social language are interwoven" (I16). One teacher, referring to how students perceived language, commented, "They don't even know how to differentiate [between social and academic language] the first three, four, or five months [when they are beginning to learn a new language]" (I12). Being asked about social and academic language created an avenue for teachers to explore and indicate their conceptualizations on the two aspects of language. For one it was a novel experience, "I never thought that much about differentiating between academic and social language" (I12). Another teacher felt that there was no difference, "Academic language is language they don't know yet or use yet" (I13).

Although interviewed teachers' remarks were similar to responses made on the written questionnaires teachers often blended the areas in their oral definitions. For example, this teacher (I22) included content, vocabulary and form.

Academic language, language appropriate for academic subjects, you know. For example if you're teaching English, you would be teaching academic language; vocabulary, like, you know, alliteration, or more formal terms that are specific for the subject matter. I guess more formal - I hate to use that word, maybe - more structured language? 
Another teacher linked context, content, and vocabulary, "Perhaps it's not just context or content....academic is also needed for survival...they need to start acquiring vocabulary that's appropriate to the context" (I5). This teacher's definition seemed to evolve as it was discussed. Others were more direct and definite. One teacher only saw academic language as form, "Academic language is grammar" (I11). Similar to the questionnaires, teachers also connected task with academic language, "Academic language is used for completing tasks" (I16). Context was mentioned for social as well as for academic language. One teacher articulated that social language was not school related, "Social language you use when it is not anything to do with school" (I14). Another teacher juxtaposed social and academic language with oral and literate realms, "Social language is when you begin a conversation... academic language is when you see it on a sheet of paper" (18). In the interview process the idea of having to instruct for academic language was commented on as it had been in the questionnaires, "Academic language is the one they receive instruction for" (I16). Possibly the most complete response was one which included content, context and task. "Academic language is used within content areas, in a school context, and in the context of acquiring knowledge and working with that information" (I23). Although some teachers had very clear concepts of what they understand academic and social language to be, others seemed to be in the process of developing definitions, and so had a certain ambiguity as to how to categorize and identify examples of academic language.

As a part of this first question, teachers were given various language examples and asked to categorize them as being social or academic. Nearly half of the 89 teachers categorized the examples as being almost equally represented by social and academic 
language. Within the examples, some elicited consensus, but others were less easily labeled. This information is summarized in Table 6.

"Giving definitions," "creating charts for data," "taking notes," "using context cues," were seen by the majority of teachers as examples of academic language. However, only "interaction in a cooperative group" and "explaining reason for an absence" were seen by the majority of teachers as examples of social language. Teachers were less able to categorize as clearly academic or social language the following examples: "responding orally to teacher's school related talk," "asking for assistance on an assignment or classroom task," "reading and retelling a story through drama or pictures," or "responding to how a poem makes you feel."

In every category, except "giving a definition," there were teachers who identified every example as possibly representing either social or academic language (see Table 6), as well as teachers who did not respond to certain examples. Four categories elicited relatively high disagreement rates. These were "responding to teachers' school related talk," "reading story, retelling through drama or pictures," "responding to how a poem makes you feel," and "asking for assistance on an assignment or task." Only two teachers thought all of the examples were academic. No one thought they were all examples of social language.

The bar graph in Figure 1 shows that teachers' definitions of academic language are fairly consistent for "giving a definition" and "using contextual cues for understanding." However it demonstrates teachers' ambiguities when categorizing examples of language such as "responding to a teachers' school related talk" and responding to how a poem makes you feel" which had no clear consensus from the 


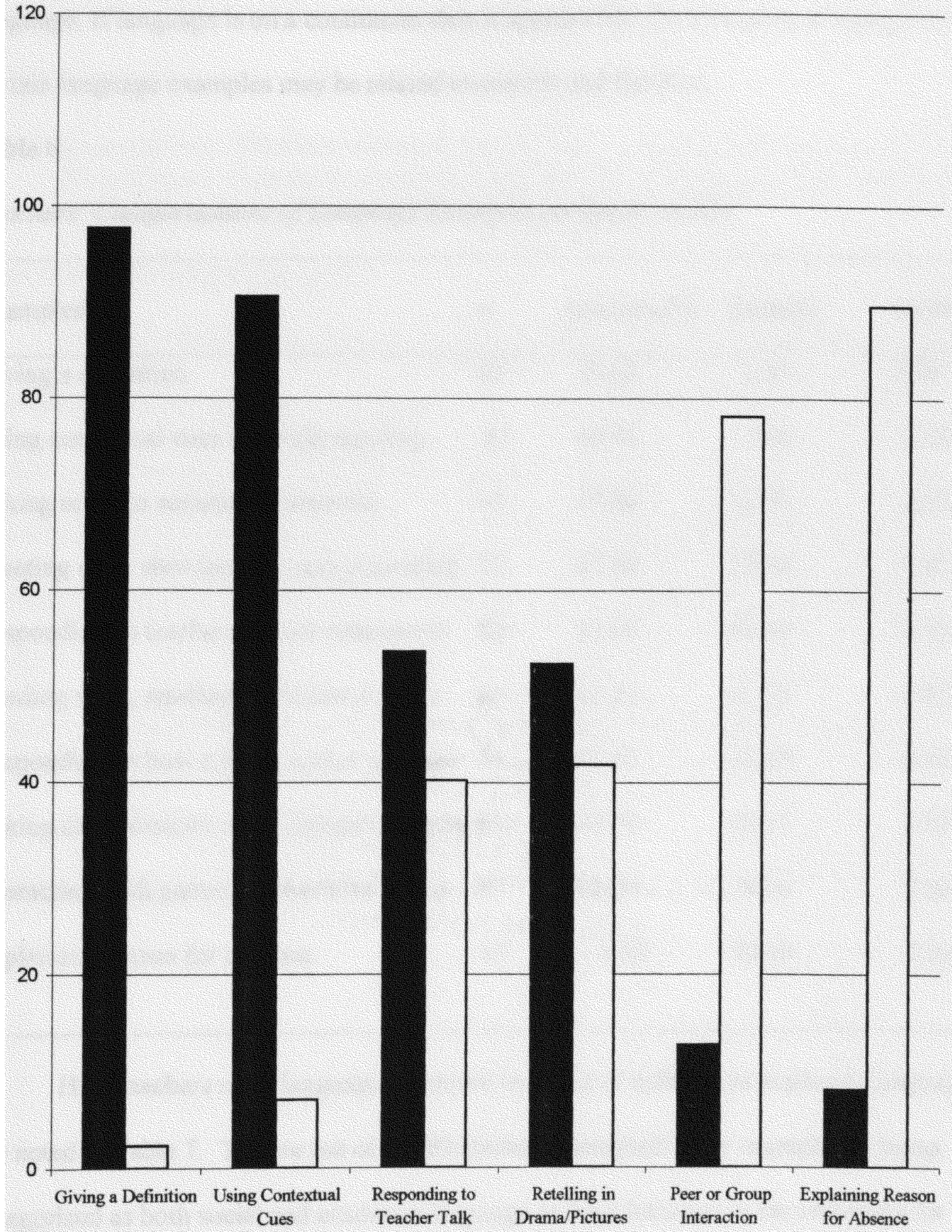

Figure 1. Teachers' categorizations of language examples. 
teachers. The majority of teachers categorized "interacting with partner/cooperative group" and "asking for assistance on an assignment/task" as exemplifying social language. If language is on a continuum then it appears that the ambiguity of categorizing certain language examples may be related to context and function.

Table 6

Teachers' Categorizations of Language Examples on Questionnaire

$\begin{array}{lllll}\text { Examples } & n & \text { Academic\% } & \text { Social\% } & \text { Both } \%\end{array}$

Giving a definition

Using contextual cues for understanding

Taking notes to summarize material

Creating chart showing data and presenting

85

Responding to teachers'school related talk 82

Reading story, retelling in drama/pictures 86

Responding to how a poem makes you feel 85

Asking for assistance on an assignment/task 85

Interacting with partner/cooperative group 87

Explaining reason for absence

85

86

87
97.65

90.58

84.88

83.90

53.66

52.33

43.53

31.76

12.64

87

2.35

0.00

2.35

2.33

3.45

6.10

9.41

3.53

64.71

78.16

9.20

8.05

89.66

2.30

How teachers rated language examples in terms of defining as academic language are noted in Table 7. Twelve out of the 89 teachers identified some examples as being categorized as both social and academic language and are included in the responses for academic language. Six or $50 \%$ of these teachers identified "interacting with a partner or 
in a cooperative group" as an example of both social and academic language. Four teachers or $33 \%$ of this same group also identified "responding to how a poem makes you feel" as an example of social and academic language.

\section{Use of Instructional Strategies}

Question Two: What instructional strategies do secondary ESOL teachers most frequently use to promote academic language with LEP students with beginning, intermediate, advanced or multiple level classes?

Data from Close Ended Questions

On the written questionnaire teachers selected from thirteen different instructional strategies for frequency use. The choices for use were "daily," "frequently," which was explained as meaning every two weeks or more frequently, "infrequently" which was explained as once a month or less, and "never." "Adjusting cognitive and language demands to linguistic difficulty" was the strategy that was used by more teachers on a Table 7

Teachers' Ratings of Academic Language from Questionnaire Language Examples

Number of Responses Rated Academic

n $\%$

$9-10$ 7

$7-8$ 18 20.22

$5-6$

$3-4$ 18

$1-2$ 1

no response 
daily basis than any other strategy. Providing graphic organizers or visuals was the second most used strategy on a daily basis. "Specific vocabulary use (less than 10 words)," was a strategy half the sample used at least bi-weekly. Nearly $40 \%$ of all teachers surveyed chose "role play and drama" as a strategy they used monthly or less. About $10 \%$ stated they never used it as a strategy. The only other strategy that teachers said they never used was "native language support within in the classroom." Eightyeight out of the 89 teachers responded to this question. About $16 \%$ of teachers said they never used this strategy and another approximately $18 \%$ said they used it monthly or less. This means that as a strategy, "native language support in the classroom" was used infrequently as a strategy by about one third of the teachers (see Table 8).

Information was gathered on the open-ended questions on the written questionnaire, which dealt specifically with strategy use as selected for classes of different levels of English language proficiency. Not all teachers taught all levels or had taught all levels in the past. Of the teachers who responded 77 of them, $86.52 \%$, provided information about strategies used for academic language instruction for beginners. Seventy-five of them, $84.30 \%$, discussed strategies for intermediate level proficiency. Seventy of them, $78.65 \%$, talked about academic language instruction for advanced levels, and 67 teachers, $75.28 \%$, spoke of the strategies they used for academic language instruction in classes with students of multiple levels of English language proficiency in a single classroom.

In discussing strategy use, a percentage of teachers listed activities or tasks instead of strategies. Examples of activities listed were: "answer questions related to a topic" (S1), "use a newspaper" (S7), "grammar fill in the blank" (S15), "write 
Table 8

Frequency Use of Strategies for LEP Students

\begin{tabular}{lccccc} 
Strategies & $n$ & Daily\% & Bi-Weekly\% & Monthly\% & Never\% \\
\hline Text Adaptation & 83 & 38.60 & 33.70 & 27.70 & 0.00 \\
Specific Vocabulary & 88 & 34.10 & 51.10 & 14.80 & 0.00 \\
Visuals/Graphics & 88 & 55.70 & 34.10 & 10.20 & 0.00 \\
Demonstrations & 86 & 47.70 & 34.10 & 10.20 & 0.00 \\
Manipulatives & 84 & 25.00 & 40.50 & 34.50 & 0.00 \\
Cooperative Groups & 88 & 44.30 & 43.20 & 12.50 & 0.00 \\
Peer Partners & 87 & 50.60 & 40.20 & 9.20 & 0.00 \\
Native Language* & 87 & 29.90 & 35.60 & 18.40 & 16.10 \\
Task Difficulty** & 88 & 33.30 & 40.00 & 8.30 & 0.00 \\
Linguistic Difficulty*** & 88 & 65.90 & 27.30 & 6.80 & 0.00 \\
Conversations**** & 88 & 52.30 & 37.50 & 10.20 & 0.00 \\
Think Alouds & 87 & 35.60 & 40.20 & 24.10 & 0.00 \\
Role Play/Drama & 88 & 11.40 & 38.60 & 39.80 & 10.20
\end{tabular}

Note. Abbreviated Forms ( Native Language* is native language support in the classroom, Task Difficulty** is adjusting cognitive and linguistic demands to task difficulty, Linguistic Difficulty*** is adjusting cognitive and linguistic demands to linguistic difficulty, Conversations**** is interactional conversations)

topic" (S1), "use a newspaper" (S7), "grammar fill in the blank" (S15), "write resumes" (S21), "label" (S79). The breakdown for each category is shown in Table 9. Listings that were neither strategy, activities, nor tasks, were also included in the responses of 
teachers. These are more appropriately labeled as content. "Subject-verb" (S81), "participles" (S14), "conditionals and literature" (S58), are examples of these listings. The single word "vocabulary" also appeared for strategies. Since there were so many using this one word response, these percentages were noted as well: $30.7 \%$ for beginners, $25.3 \%$ for intermediates, $17.1 \%$ for advanced, and $8.9 \%$ for multiple levels within a class.

Of the strategies teachers listed, there were four that were always named for each level of English language proficiency: "graphic organizers or visual supports," "groups or partners," "modeling," and "role play or drama". Although these strategies were consistently listed, there were varying percentages of reported use for each of the different proficiency levels. These four strategies and percentages are shown in Table 10.

Table 9

Teachers' Listing of Strategies or Tasks/Activities Based on Level of English Proficiency

\begin{tabular}{lccccc}
\hline Level & $n$ & Strategy \% & $n$ & Task/Activities\% & $n$ \\
\hline Beginners & 78 & 52.56 & 41 & 47.44 & 37 \\
Intermediates & 75 & 57.10 & 31 & 58.66 & 44 \\
Advanced & 70 & 27.14 & 19 & 72.86 & 51 \\
Multiple levels & 67 & 71.64 & 48 & 28.36 & 19 \\
& & & & & \\
\hline
\end{tabular}

For beginners, a total of eight strategies were named. The percentages, with actual numbers $(n)$ of teachers in parentheses, are as follows: graphic organizers/visuals, 
Table 10

Four Strategies Used for Various Levels of English Language Proficiency

Strategy

Beginners\% Intermediates\% $\quad$ Advanced\% $\quad$ Multiple Levels\%

$\begin{array}{lcccc}\text { Graphic Organizers } & 24.36 & 18.60 & 14.29 & 14.93 \\ \text { Groups or Partners } & 12.82 & 18.67 & 9.33 & 56.72 \\ \text { Modeling } & 7.69 & 4.00 & 2.86 & 2.99 \\ \text { Role play/Drama } & 11.54 & 4.00 & 2.86 & 7.46 \\ \text { Total } & 78 & 75 & 70 & 67\end{array}$

$24.36 \%$ (19); native language support, $14.10 \%$ (11); groups/partners, $12.82 \%$ (10); modeling, $7.69 \%(6)$, role play/drama, $11.54 \%(9)$, text adaptation, $3.85 \%(3)$, demonstrations, 5.13\% (4), and Total Physical Response (TPR) 6.41\% (5). The top two strategies for this group were the use of graphic organizers and native language support within the classroom. The use of graphic organizers or visuals provides contextual support for students who are just beginning to acquire the language. That coupled with native language support should provide additional comprehensibility of the instruction.

Intermediates had the same strategies listed, but all were mentioned less except for text adaptation and group/partners. For this proficiency level 5.33\% (4) of teachers listed text adaptation, opposed to the $3.85 \%$ for beginners, and $18.67 \%$ (14) listed group/partners compared to $12.82 \%$ for beginners. Reported use of strategies were: graphics/visuals $18.67 \%$ (14), native linguistic support $2.67 \%$ (2), groups/partners $18.67 \%$ (14), modeling $4.00 \%$ (3), role play/drama $4.00 \%$ (3), text adaptation $5.33 \%$ (4), 
demonstrations $4.00 \%$ (3), and TPR $1.33 \%$ (1). Two teachers specifically mentioned their strategies for academic language acquisition for intermediates was "English only" (67) and "no native language support" (77). This was the only level where these comments were noted. It appears that at this level teachers are more likely to have students working in dyads and with texts that are adapted to less proficient students. The social interaction of peer partners combined with text adaptations may help this level bridge to more academic language and more cognitively demanding tasks since they receive support linguistically and task support through working with peers. It is as if teachers are acknowledging by these choices of strategies, that intermediate students are beginning to be more independent learners, but still need assistance as they deal with more context reduced and abstract language.

For advanced LEP students, one less strategy was named by teachers. Additionally, this is the only level where modulation of language for cognitive tasks was listed. Otherwise, the percentages were as follows: graphic organizers/visuals $14.29 \%$ (10); native linguistic support $1.43 \%$ (1); group/partners $10.00 \%$ (7); and modeling, role play, and demonstrations each had $2.86 \%$ (2) of the respondents.

Many teachers have multiple level classes. English or Language Arts Through ESOL is the grade level content course for secondary LEP students. Unless the LEP population of a school is quite large and scheduling quite deliberate, classes will be made up of students of the same grade level, but different levels of English language proficiency. This configuration is challenging to teachers. The listing of strategies for these multiple level classes was higher than any other levels. Sixty-seven teachers responded to this question and 48 of these teachers specifically listed strategies and not 
activities. One strategy in particular was mentioned overwhelmingly: groups. For all 67 teachers, $56.72 \%(38)$, reported using grouping as a strategy. However out of the 48 who specifically listed strategies for this classes, 38 of them, or $79.17 \%$, chose cooperative groups. Three teachers specified the responsibilities or how group members should be used: "pairs of students teach each other" (S22), "advance students translate to lower" (S33), "need other proficient students to help assimilate" (S44). The rest of the strategies chosen for the multiple level configuration were graphic organizers/visuals, $14.93 \%(10)$; modeling 2.99\% (2); role play/drama, 7.46\% (5); and 1.49\% (1) each for native linguistic support within the classroom, text adaptation, demonstrations, and modulation of task due to linguistic difficulty. Across this population of teachers the use of graphic organizers remained at $14 \%$ or above for all levels and class configurations which shows consistent use of a particular strategy for LEP students. Additionally, when challenged with multiple levels within the same classroom teachers are inclined to use group formations as a strategy for instruction.

The data from the open ended questions were parallel on some strategy use and contradictory on others. When elicited, teachers named tasks and strategies, as well as listing the word "vocabulary" without further explanation. Consistent with the data from the close ended questions on the questionnaire was the use of visuals and graphic organizers and cooperative groups and peer partners. However, "adjusting cognitive and linguistic demands to linguistic difficulty" was not mentioned in the open ended questions possibly because modulation of task and language is probably automatic behavior for ESOL teachers and no longer thought of as specific strategy. Also, the strategy "role play/drama" which was mentioned consistently by teachers in open ended 
questions was selected in the close ended questions as either being used infrequently or not at all by nearly $50 \%$ of teachers.

\section{Descriptions of Instruction}

Question Three: How do secondary teachers describe their instruction for promoting academic language?

In answering this question, it became apparent that how teachers described their instruction was influenced by how they defined academic language. The information gathered from interviews of 23 teachers were used to provide the answer to this question since the interview format allowed more opportunity for subject probing. Teachers had difficulty articulating how to specifically instruct for academic language. To help them try to formulate a response the interviewer asked them to describe what someone might see them doing if they came into their classroom. That helped to elicit more description of what might be occurring in the classroom. Form and content were the themes mentioned most consistently during the interviews as the foci for academic language instruction.

\section{Description as Grammar}

Teachers who defined academic language with form tended to emphasize and instruct for language structure. The following teacher's (I11) response demonstrates this point.

Academic is grammar for me...I do a lot of sentence structure, a lot of verbs, transitive and intransitive. I do them changing verbs. I do basically anything in grammar...There's this huge difference between the social and the academic in terms of - in terms of instruction, in terms of process... if I am doing academic language, I will tell them exactly what I'm doing. I mean, I don't go around beating around the bush. We talk about it. I never play a game where I would instruct something and let them figure out. No, I tell them the rule, with academic 
language, I do. ...When I do academic language... it's like going through an instruction book.

Another teacher (112) explained her views and instruction through form, but also in terms of text.

Well academic language, to me, is something that is definitely grammatically correct. And then, with the clear ideas, not getting off on tangents, having the student stick to the topic, giving proof of his ideas, his or her ideas. And then I would also go into teaching synonyms, not repeating the same words, going into different types of sentence structures using complex sentences, longer sentences, advanced grammar...I would probably say what I teach is fundamental academic language, but I have to tell you, I never thought that much about differentiating between academic an social language... Academic language includes grammatically correct language...I'm a grammarian at heart. I enjoy teaching structure, and I just enjoy teaching the language itself.

One of the teachers (I17) who defined academic language with form also included content within the definition and explained her instruction through it.

Academic language is, to me, a standard English that they find in books and the proper rules of grammar and writing and reading and so on...that's my definition, but there's some blurring... I tell them, 'This is basically proper English. This is the expected English, the one that you are going to be expected to write when you write term papers'... I mean a short biography written of themselves in proper English, I would consider that academic language...I do make a distinction about what is social and allowed outside the classroom and what is academic...social language is interaction before the teaching begins. I actually communicate with my students using social language... but when we're discussing something that has to do with literature, we use literary terms and things like that, which I consider academic language...we do a lot of literature and we do critical thinking skills... once you go into higher-level thinking skills, the language that I expect from them has to be academic.

Another teacher (12) tied form to the writing process as a way of explaining how to instruct for academic language.

Academic language is what they write and the grammar that they use when they write and how they express their ideas and the organization they use to express the ideas that come across clearly... [how they instruct for academic language] by asking more comprehension questions, by asking them to do exercises of organizing their thoughts, then diagrams, pros and cons lists, things of that 
nature...I try to make the examples as real to them as possible in a language that is comprehensible to the level of the student...For the level one, I try to be a lot more concrete...I always try to relate my lesson to their personal experience, because I think that is how they can relate to grammar better.

\section{Description as Content}

Teachers who defined academic language in terms of content focused on the text or specific language arts content which included vocabulary and reading comprehension when discussing their instruction. This teacher's (I4) is a typical response.

Academic language is usually basically from the text. We go and we do vocabulary and comprehension. It's usually mostly from the text...I question them about prior knowledge...then we will read the story and chunk it... we discuss different sections, and then we go on from there...there's a lot of communication between the students and myself...things written on the board.

Another teacher (I8) explained her instruction in terms of her particular curriculum.

I teach just the literature through language... When I am getting ready to introduce a new piece of literature, I use visuals. I use realia...I elicit prior knowledge from the students. In some cases, social language comes in there because they're helping each other with-'Oh yeah, what's that word in English? Here it is in Spanish.' The kid can come up with the answer in Spanish, because they do have prior knowledge. They do have academic learning in their minds, but to say it in the second language sometimes is a problem... One of the things I feel I need to work on is I'm doing much too much lecture, show and tell. I need to do more with the kids interacting and learning from each other.

Using "Beowulf" a teacher (I22) described her instruction in detail via the story.

If I am teaching a story, the first thing I do is I go over the vocabulary before we even attempt to read it. I pair the kids off in groups, so they can help each other out with instructions I give. If they don't understand they kind of help each other through it...I told the kids, you know don't worry that you don't get every little thing...I picked out words that I thought were important and we did some active reading questions along the way. I taught them how to clarify and how to make predictions and they were actually able to do it...I try not to spoon feed the literature too much... but give them some guided questions, that has worked for me...they can do a lot more than what you might give them credit for. You think, "Beowulf"! Oh, my God! I can't imagine teaching that... but it's incredible to see what they can understand and what they can do... lately, what I've been doing is having them share in the work...then we'll all come together as a group and 
orally, you know they'll say their answers. That way, everybody's doing a little bit and they are all benefiting.

\section{Description as Context}

Two teachers explained their approach to instruction using context with content.

The first teacher (I5) initially spoke about content, but as she continued her description

she spoke more about context.

I was thinking more the academic language is what the students need, what's necessary for them to succeed in their content area classes. The academic language is what they need to survive in school, to do well in school...You're teaching them different types of language. You're teaching them one language, but you're teaching them language in different contexts....the social context, and then there's the academic context... you automatically teach them or instruct them or guide them as to the appropriate way that they need to ask or answer in a social context or in an academic... you help them to discern between one and the other... you know they need to start acquiring that vocabulary that's appropriate to the context in which you're studying, whether it's social studies or science... perhaps it's not just context, because of course, in your language arts class there's academic then there's social.

The other teacher (I23) remarked that she used contextualization and conceptualization to teach academic language.

I try to present academic language sometimes within a social context...I look at vocabulary and context and cognitive thought processes that are connected to certain aspects of language and content are of vocabulary...I find that I try to tell, like stories, sometimes, to demonstrate certain concepts. For example, when I was teaching point of view, I told the kids this story about something that had happened, so that they would understand that this person was giving her point of view, that person was giving their point of view, that other person was giving their point of view. I try to embed it into a story, so that they get the concept. I try to conceptualize things... within the context of literature and understanding the structure of literature and understanding fictional elements and qualities of the discipline that would be vital to being able to discuss literature... for example, plot structure or point of view, things like that, I would focus on and be sure that the vocabulary is there...I contextualize...try to use more visual supports and more back and forth comprehension checks. 


\section{Limited Description}

A teacher (I3) who had said that she did not differentiate between social and academic reiterated this when she explained her instruction.

There's not enough of a difference to make for a different kind of instruction...I structure my instruction... the natural language way... you realize, I am not used to explaining myself... In general, I introduce the things orally first. I think that everything should be understood orally first. I don't think you should start writing until you can speak. I'm not in favor of teaching students writing skills until they're at least level two or three, because I think that that's just a waste of time, to be writing before you know what you're doing. I guess it's all back to the natural acquisition, again. I think that you should learn it the way you learned your own language. You didn't start writing you own language until you understood it, then you started writing it. So, I don't see why people would start trying to read and write or trying to write in English before they understand English. I spend a lot more time on understanding, listening comprehension. I do a lot of listening comprehension and a lot of speaking.

When asked how she judged when they had enough English to make the transition from the oral realm to the written she answered, "When they start saying things like, the bell rang."

Although the teachers discussed how they would instruct for academic language or what someone would see within their classroom as they instructed for academic language, there was no single distinction that emerged from their descriptions in the interviews of secondary teachers. However there were indications that teachers' conceptualizations of academic language affected their choices for instructional delivery. Based on these responses and previous information from the open ended questions of the questionnaire there seemed to be four different teacher voices which emerged from that data and reflected teachers' conceptualizations of academic language: the voice of grammar, the voice of content, the voice of context, and the voiceless. Teachers who defined academic language in terms of form were grammar oriented in their description 
of instruction. Teachers who defined language in terms of content used it as the centerpiece of academic language instruction. Teachers who defined language in terms of context used it to move through instruction. Teachers who could not specifically articulate their ideas also had difficulty explaining how they planned their instruction.

\section{Differentiations of Teachers' Strategy Use}

Question Four: Are teachers' descriptions of their strategy use differentiated on the basis of: (a) the level of students ' proficiency in English, (b) teachers' professional preparation, (c) teachers' own language background?

The strategies teachers had described as their choices for instruction of LEP students were examined to see if there was any significant difference of use. Using Chi Square, data was examined to see if there was an association between the strategies teachers used and students' level of English proficiency. When teachers listed their levels they represented more than just the levels labeled as beginners, intermediates, advanced and multiple level classes. Teachers had classes that mixed two levels, or had a variety of different types of classes and reported all uses together. Therefore the wide range of descriptions of class configurations affected the outcomes. Using Chi square, it was found that there was no significant difference of strategy use for different levels of LEP students.

Teachers' professional preparation was another area examined. Chi Square was used to examine association between the teachers' reported use of strategies and teachers' professional preparation by graduate or undergraduate degree. For the strategy "adjusting cognitive and language demands according to task difficulty," the difference was marginally non-significant, $x^{2}(2, N=89)=1.62, p=.059$. "Native language support within the classroom" was marginally significant, $x^{2}(3, N=89)=7.63, p=.054$. Both 
of these results suggest that there may be little relationship between professional preparation in terms of graduate or undergraduate degree and the use of these two particular strategies. In the case of the third category, an association between teachers' native language background and the strategies they used for LEP students was examined. The results indicated that there was no association between teachers of different native language backgrounds and the strategies they use for LEP students. Based on this information, when teachers selected from a list of strategies, it appears that their overall strategy choices are not related to students' levels of English proficiency, teachers' own native language background, nor professional preparation.

Congruence Between Descriptions and Practice

Question Five: Are teachers' descriptions of the strategies they use to promote academic language proficiency congruent with their daily practice?

From the 23 interviews, approximately 16 hours of classroom observations were conducted with 10 teachers. The majority of these teachers described what they do to promote academic language or described their instruction within the classroom that was matched with their instruction in the classroom on the day observed. There was a lapse of time of approximately two months between the interview and classroom observations for seven out of the 10 teachers and a month for one teacher. Two teachers had observations within a week and a half of their interviews. It is highly unlikely that they would have remembered the content of their interview and tried to enact it in the classroom. Therefore it is presumed that what was observed in the classroom was a credible representation of teachers' operationalization of their concepts of academic language instruction. 
What teachers reported as doing to promote academic language through their instruction was evidenced in classrooms observations for seven out of the ten teachers. Comparison was accomplished by looking at the transcripts of their specific descriptions of how they instruct for academic language and matching it to what was directly observed during the classroom visitation. The teachers used a variety of strategies, many of which were not mentioned in their interviews. However, this question focused only on the congruence between teachers' description of instruction and their actual observed instruction.

Two of the teachers had inconsistencies between what they said they did and what they actually did in the classroom or were not specific enough in describing their instruction to provide comparisons. One teacher had been very broad in the description of what was done in the classroom for academic language instruction, nevertheless a comparison was attempted. It was noted that teachers spoke more easily about what they do in the classroom than what they do specifically to promote academic language. The following three vignettes are examples of congruence of these various teachers' descriptions and the observed instruction.

Teacher I23's classroom was visually impressive. Posters on the wall were varied and eclectic: the alphabet in manuscript, a world map, capitalization rules, and types of genre. In the front of the room was a map of the United States constructed from postcards of the individual states, the Statue of Liberty jutting up through its center. Student work was dotted and splashed throughout the room. On this particular day, the teacher was giving a lesson on textbook structure. "Let's start looking at the text book and how to use it, perhaps there is more here than meets the eye. What do you think I 
mean by that?" Various students gave suggestions, until finally one offered, "more than what you see?" The teacher confirmed this and directed the class' attention to the cover. They were asked to describe what they saw. When the title was mentioned, the teacher elicited predictions and had a discussion about what it could mean. A student mislabeled the publisher for the author. The teacher explained the idea of a publisher. Then the teacher moved into the text. They were asked to look at the things that caught their attention, specifically to look at illustrations. They discussed the different pictures that they liked or thought were interesting. The teacher made the statement, "Textbooks are used differently than reading books," and had the students generate ideas about this. The class came to consensus that textbooks are used, reading books are read. At this point the teacher began to go through the book introducing specific terminology with explanations as she came to it: table of contents, copyright page, acknowledgements.

In discussing how she instructs for academic language, this teacher commented on her trying to contextualize language. One of her strategies was to try to "embed" or "demonstrate" concepts. Her using the book was a way to embed the context for the students. She also remarked that she doesn't differentiate between social and academic language when teaching, but when focusing on vocabulary she tries to get students to understand it within the specific context and then use it within the same context. This was seen in the discussion with students and as she had students use the vocabulary or specific terminology to discuss their points. She stated that sometimes she tries to present academic language within a social context and offered as an example telling a brief story to embed a concept. This was not seen in the lesson, nor was the back and forth comprehension checks for assessment purposes observed. She also stated that she 
used a lot of visuals and graphic supports. This was readily seen with her use of the book and also with the visual verbiage within her room. Things were not individually labeled, but there was an abundance of pictures connected to text. On her board was a web with a short word bank that remained from the previous day's lesson. On the tops of the boards were quotations and thoughts. Students in her classroom are surrounded by language.

Teacher I2's class was a large computer lab. Many things are labeled in the classroom, "clock," "plug," "pencil sharpener," "red light." There were posters of punctuation and capitalization rules, numbers, colors, the importance of reading, and cooperation. The teacher began with, "What day is today?" Students were allowed and encouraged to use previous notes as the teacher rapid fired questions about days and dates using the present, past, and future tenses. She alternated between the concept of day and date. She related this to students' birthdays and school. Students were sent to the board to write numbers that were dictated, both numeral and written word. Students at their desks were told to do the same to verify correct answers. All of the words used were a part of a vocabulary given previously. The teacher linked what she was doing to the math area and basic skills of writing checks. At certain points students asked for clarification in Spanish and she responded in English. When several more students began asking in Spanish she required that they ask in English, which they were able to do without difficulty. She moved on to a lesson on pronouns. She contextualized the use of pronouns by using students in the classroom and also objects. She then went on to classroom commands using TPR and then having students use those for other students. She ended the class with a review of question words: "who," "when," "where," "what," "how," "which," and "why." When she had discussed academic language she had 
defined it as "what they write and the grammar that they use." In her class, students relied on the printed word via their notes and what they generated on the board. Her students kept their notebooks open throughout to refer to charts and lists from previous classes. In describing her instruction she said that she used lots of comprehension checks, diagrams, lists. Her verification on comprehension was constant throughout the class. She had also talked about how she tried to make the examples as real as possible at a comprehensible level and how she tried to "relate my lesson to their personal experience." This was seen in her efforts to connect to birthdays and direct commands by students, as well as the usage of individuals for pronouns. She also reported grouping students by levels in her language arts class. This class, however, was an all ESOL reading and writing elective for level one and there were no groupings noted here, presumably because they are all the same proficiency level.

The students in teacher I4's class were engaged in writing when we entered. They had been left with a prompt to respond to in the first few minutes of class time. They were given a few more minutes before being stopped to read and share what they had written. They then began the next topic: nouns. This was a review. There was a visual support, a chart, on the board. Students provided definitions and also distinctions between proper and common nouns. The teacher created another basic chart and elicited examples from them to place in the chart. When they were unable to do this she referred them back to their notes and they had to verify information from a previous class and generate original examples. They were then given new word lists and had to create their own charts for classification purposes. The majority of students appeared to understand and were on task. Students who did not understand sought clarification from other 
students in Spanish or from her. Since she was moving around the classroom from student to student this was easy for them to do. Although she is not a Spanish speaker, she understood what was said and made every attempt to communicate and clarify points. When students seemed to have difficulty understanding she would continue to give them examples, or reword until they got what she was conveying. When she described her instruction for academic language she talked about how she walks around and interacts with students on an individual level.

They would see a lot of communication between the students and myself. They would see things written on the board. They would see me walking, checking the students to be sure that they're on task...trying to check - especially the ESOL ones, if they are understanding something about what we're doing.

The following two vignettes are examples of teachers who had difficulty differentiating between social and academic language or in articulating their instruction for academic language development. One of the teachers (I3) who had difficulty in differentiating social and academic language finally decided that there is no difference between the two and stated that she introduced things orally first and that the students shouldn't start writing until they could speak the language. When she was asked about how she introduced vocabulary her response was, "I have no set rule." When asked if she used graphic organizers, she responded, "I'm not good at them." When asked if she ever grouped students she said "all the time." She was asked why they were grouped and she replied, "because they're better in a group than they are alone." She said that most of the groupings were random though she might occasionally group by proficiency level.

The first fifteen minutes of her class was designated for silent reading, but students so disrupted the class that the teacher terminated the activity. They were then 
directed to write about whether or not they would recommend the book they had been reading. There were no specific directions and the majority of students were off task and remained so. A few minutes after getting two students to share their writings she began a grammar lesson. There were 35 students in this class, but they were sharing seven books. She told them they were in collaborative groups and they would do the work orally. No one in the groups seemed to know what to do. This was an exercise on the comparative and she set up a repetition drill that alternated from individuals back to the group. Concepts were not explained or extended. At one point the teacher stated that she didn't differentiate between the content class of language arts and the reading elective class for proficiency levels. Her comment was, "It doesn't matter anyway." This was correlated with her remarks on social and academic language. She also had not seen a difference between the two.

One other teacher (I1) stated in her interview that she teaches that "language has components." She said she used readings as a "springboard for teaching" and she gives students the concepts and definitions and "things like that... we deal with that on the recognition level, getting them to recognize, in a given line or stretch of language, high prevalence, you know, things in that line." Since she was not very specific, I asked her to explain what someone might see her doing if they came into her classroom. She stated that with ESOL 1 students "things could be broken down. It could be simplified...I could give them much prompting... with ESOL IV's, I mean, those whose proficiency level is III and IV, with them just things are far more complicated." When asked to further explain this, she didn't provide any more specificity. 
This teacher began by writing four questions on the board to activate prior knowledge and generate a discussion. Neither questions nor terminology within them were explained. Students were asked to read an article aloud, taking turns when called upon. Many of these students had difficulty decoding words, even high frequency words. No corrections of any type of pronunciation error were made by the teacher. For example, one student said, "disintegrate" for the word "denigrate." They were asked to determine the position of the writer in the article, but did not have to give justification for their opinion. Students were confused by the term in the article, "politically correct." It was explained that political correctness varies from context to context, society to society, but no further explanation was given. In the middle of the discussion, and without connection to previous statements, the teacher made this statement, "A second language is power. We here are not teaching you about the language, we are teaching you the language." She digressed and talked about Galileo, Newton, and Aristotle, then asked the students to write. They were quite confused about what to write. Finally, they were given a choice of topics. After a few minutes students read what they had written. No comments or corrections were made. At one point she commented that genocide and "genocide" is the same in Spanish and English, but did not discuss cognates, nor clarify what genocide is for the Chinese and Creole speakers. She disclosed that she uses the same reading selection all day long no matter what grade she is teaching and adapts it for the levels. She was next observed teaching a higher level class, but no change in instructional style nor presentation was noted.

This final vignette is of a teacher whose description of her instruction for academic language development was broadly stated and who did not delineate specific 
strategies. When asked to describe what someone might see her do for academic language instruction Teacher $\mathbf{2} 20$ responded, "I do almost everything: reading, acting, group work." Her definition for academic language was "the one that a student needs to get information about different subjects." Her classroom of over 40 students was one of the largest classes observed. It was quite bare, with one single poster, "Solve and Succeed," plastered on the wall. The first few minutes of class was devoted to what she referred to as "housekeeping." Then she began instruction by returning the previous day's vocabulary test. There was a lot of interaction among students in Haitian Creole interspersed with some chunks of English in response to vocabulary test answers and scores. The teacher then began a discussion of analogies and how to look at them, since this was one of the items they had been tested on. Students seemed aware of the terminology and concept of analogy. She chose an example that most had gotten wrong and talked them through their thinking. Then she re-explained through thinking aloud how to arrive at the correct answer. There was a lot of back and forth interaction from teacher to student and student to student on the topic. After this, she began the next activity starting with a review. She elicited the definition of "run-on." She probed students until they produced the word "clause" and then got them to explain and identify a clause. She asked students for examples of sentences and how ideas could be connected within them. Using these examples she broke specific sentences down, eliciting academic language from students, and got them to clarify each part of the process. She then elicited more sentences orally. When given a sentence, she turned it into a dictation and had the students write it as she repeated it several times. Finally, she wrote it on the board for any student who may have not been able to get it from dictation. 
There was tremendous interplay between teacher and students. They seemed quite accustomed to this particular approach and were very responsive in interactional conversations with the teacher and each other. She asked for information, clarified or restated their information, queried students to verify the information and in so doing drew out specific terminology and reinforced the students use of it. Her description of "I do almost everything," though broad and global was borne out in this classroom observation.

Although definitions or conceptions of academic language and instructional practices were congruent this does not mean that it can be concluded that all instruction was of an academic nature. What can be concluded is that there are indications that teachers' conceptualizations of language whether they are voiced in grammar, content, or context influence their instruction. Even for the "voiceless" teachers who could not articulate their conceptualizations, the absence of definition was also observable in the classroom. Individual teachers' instruction matched their own description. For the most part, what these teachers said they did, they did. Theories of practice and theories of use converged in their classrooms (Argyis \& Schon, 1974).

Summary

This study focused on what secondary ESOL teachers understand about social and academic language and the instructional strategies they use for LEP students. Teachers' definitions of social and academic language are still developing. There are some ambiguities about what constitutes social or academic language, as well as disparity in categorizing social and academic language. Certain examples were either readily identified by the majority of teachers as academic language or social language, whereas there was lack of major consensus on many other language examples. 
In terms of choices of strategies, graphic organizers were used the most consistently across all levels of English language proficiency. In their focus, teachers were mostly task oriented with advanced LEP students. Yet, with beginner and multiple level classes, teachers were more strategy oriented. When faced with the challenge of a multiple level class configuration, the overwhelming majority of teachers incorporated the use of cooperative groups as their main strategy.

Teachers tended to describe their instruction for academic language in one of four ways. They articulated it in terms of either a grammar, content, or context perspective, or they were not able to articulate it.

There was no significant difference for strategy use associated with teachers' native language background, or student's levels of English language when teachers chose strategies for LEP students. Neither was there a difference based on teachers' professional background except, "native language support within classroom," which was marginally significant and "adjusting cognitive and language demands according to task difficulty" which was marginally non-significant.

Teachers who formulated conceptualizations of academic language incorporated them into their instruction. Their descriptions of their instruction were borne out in classroom observations.

The results of this study that are the clearest revolve around teachers' descriptions of the strategies they use for LEP students. Teachers have formulated ideas of what strategies they think should be used for these students, as well as how to foster the development of academic language. This may be influenced by their years of experience in teaching English to speakers of other languages or from their professional preparation 
or a combination of both. Additionally, their instruction reflects their specific understandings of what they believe should be done to promote academic language. What still remains unclear, however, is the conceptualization of academic and social language. Additionally, there remains a question as to whether or not the strategies teachers choose for LEP students are used sufficiently, and whether or not they are effective in promoting academic language acquisition in a secondary school population. 


\section{CHAPTER V}

\section{DISCUSSION}

Conversations with teachers as they negotiated through curricular change provided the impetus for this study. The field of English as a second language is a relatively young one, still evolving and, as such, malleable. As research is conducted and information is gathered understanding and definitions of language have been developed and expanded. This malleability is reflected in the continued delineation of language proficiency at state and federal levels, resultant policy changes for the LEP population, and changes in educational practice to correlate with the definitions. Keeping abreast of the changes, and adapting new knowledge to practice, challenges teachers and policy makers.

\section{Study Focus}

Although ESOL teachers are frequently familiar with the terminology of social and academic language, they may have greater preparation in oral language development (Au, 1993). In the area of second language acquisition it is assumed that the organization of instruction is dependent on a clear understanding of language proficiency.

Furthermore, what strategies teachers use to facilitate language proficiency may be bound to their conceptualizations. However being able to specifically define, identify, or exemplify social and academic language may be difficult for teachers, and may vary based on myriad factors such as their own teaching experience, manner of entry into the field, or professional preparation. Therefore, this study was done to examine what 
secondary ESOL teachers know about social and academic language, what instructional strategies they use, and how this translates into daily classroom practice.

\section{Methodology}

Since an integrated view of what teachers know and do was the focus of this investigation, it was decided that the collection and interpretation of data should be both quantitative and qualitative and be a mixed method study. A questionnaire, sent to all secondary ESOL teachers, gathered information on teachers' conceptualizations and categorizations of social and academic language, and choices of instructional strategies and frequency of use. Approximately $29 \%, 89$ of the full time ESOL teachers in the district, responded to the questionnaire. Both closed and open-ended questions were used, but individual interviews were conducted to gather more extensive responses and probe for additional information. Twenty-three teachers or over $25 \%$ of the respondents who answered the questionnaire were interviewed. To examine the congruence of their espoused theories of action and theories of use (Argyis \& Schon, 1974), classroom observations were conducted with 10 teachers, approximately $40 \%$ of the teachers interviewed.

\section{Summary of Findings}

Each research question was answered using different data and interpretations. The first question sought the criteria that secondary ESOL teachers use to differentiate between social and academic language. Additionally, language examples were given for categorization as either social or academic language. It was found that the criteria that teachers used for social and academic language emerged from theory and practice. "Content," "vocabulary," "form," "task," and "context" were the areas of differentiation 
noted by teachers. "Context" and "form" were most often used to delineate social language, whereas academic language had more varied, and not as clear-cut responses. The most frequently mentioned delineator for academic language was form, with content and context following.

In categorizing the language examples, there were certain instances where the majority of teachers clearly had consensus and determined that the language was definitely academic or definitely social. However, there was not $100 \%$ agreement on any of them. Other examples were split fairly evenly between the social and academic categorization reflecting an ambiguity in identification.

The use of instructional strategies was a second focus in this study. On the questionnaires, over $90 \%$ of teachers reported using peer partners and adjusting cognitive and language demands according to linguistic difficulty at least twice a week or more. Least frequently used were "manipulatives" and "native linguistic support within the classroom." However, in the interviews four strategies were consistently named for each level, albeit with differing percentages: "graphic organizers or visual supports," "groups or partners," "modeling," and "role play and drama." Both beginners and multiple level classes had more strategies reported being used than other levels. Advanced level classes had the least amount of strategies reported, as teachers focused more on tasks than strategies. Graphic organizers were used consistently across all levels and the use of cooperative groups was the primary strategy listed for instruction with multiple level classes.

Additionally, in examining strategy use for LEP students, when teachers selected from a variety of strategies there was no significant difference found in teachers' choices 
of strategies based on students' English language proficiency, teachers' professional preparation, or teachers' own language background.

Teachers' definitions of social and academic language and their strategy use for instruction were related. Teachers' descriptions of their instruction were influenced by their understandings of academic language. Teacher prototypes emerged from different perspectives of academic language: the voice of grammar, the voice of content, the voice of context, and the voiceless. The embodiment of these prototypes was found in teachers' instruction with a high level of consistency. Teachers' conceptualizations influenced their instruction.

\section{Discussion}

Based on this investigation there are indications that this population of secondary ESOL teachers are in the process of evolving their definitions of social and academic language, and are at different stages in this evolution. Furthermore, there appears to be a strong link between teachers who have clear constructs of language and their ability to operationalize these constructs within their instruction. Some teachers are able to infuse their practice with their understandings and demonstrate congruence between their theories of action and theories of use (Argyis \& Schon, 1974).

Four teacher prototypes for academic language emerged from the questionnaires and interviews. Teachers' definitions and examples of academic language fell into recognizable categories. The prototypes of the evolution are: the voice of grammar, the voice of content, the voice of context, and the voiceless. Teachers' individual instruction embodied their voice. The voice of grammar focused on structure and language itself. The voice of content wrapped language around particular subject matter and concepts. 
The voice of context wove language back and forth through concepts. The voiceless could not articulate their constructs and therefore gave amorphous instruction, instruction that had limited academic focus or purpose.

What about social language? Secondary teachers seemed driven to develop academic language and gave the impression that social language can take care of itself and develop through relationships. This drive for academic language may be fueled by the limited amount of time left for formal schooling for this age group, and the burning need for these students to acquire sufficient skills to meet graduation requirements and perform on to an adequate level on standardized tests.

It seemed from the comments given and the lack of mention of social language as being directly taught, that it is the language to "be" in, and can develop on its own, and academic language is the language to "do" in, and must be actively developed. However, students must develop social language in order to negotiate through school culture and eventually participate in society. So, it can not be assumed that adequate acquisition of social language can be developed naturally without instruction. Nor should one aspect of language development be neglected because it is not perceived as being as important. The sequential process of social and then academic language acquisition, as one teacher remarked, is indicative of the importance of having two aspects or dimensions of language developed.

In specific strategy use there appears to be consistency of particular strategies for LEP students: graphic organizers or visual supports, modeling, role-play or drama, and use of groups or partners. There appears to be an all out onslaught of strategies for those beginning to acquire a second language especially if they are novices. However, as they 
reach a more advanced level of English language proficiency, the emphasis of teachers shifts to tasks, away from the more context embedded language, and becomes more cognitively demanding. What happens in the multiple level classroom as reported by these teachers is less variety of strategy use overall, with the strategy of choice being cooperative groups. This could indicate that teachers are attempting to address the language needs of advanced students and promoting tasks, while trying to also develop those more rudimentary language skills in the less proficient students. Using groups may be a way for teachers to provide native linguistic support for beginners, create opportunities for social language development, and maintain the integrity of academic language development by being less contextualized and more cognitively demanding for all levels. It may also be a way of facilitating academic language acquisition via social interaction or it may be only social interaction with limited academic language development.

Relationship to Prior Research and Theoretical Implications In a previous study, 66 percent of educators who responded to a questionnaire on academic language stated that they explicitly taught academic language, and the remainder stated they did not. Almost 60 percent of them identified vocabulary as a key feature of academic language while approximately 40 percent described academic language in terms of activities (Solomon \& Rhodes, 1996). In this current study, vocabulary was infrequently noted as a delineator in defining academic language, but was mentioned more often in describing instruction for academic language, especially for beginning and intermediate LEP students. As in the previous study, task was described as indicative of academic language development. Examples of tasks might include 
analyzing a passage for tone, or constructing a chart that synthesizes information. For the groups of beginners and intermediates, a similar $40 \%$ of educators designated task for academic language. However, in the current study this increased dramatically for advanced levels, and then dropped almost as precipitously for multiple level classes, an aspect not examined in the previous study.

Contrary to Constantino's study (1994), where teachers articulated a common belief about comprehensibility and language acquisition and development which did not play out in their classroom descriptions, this current study indicates that teachers who have clear constructs of language can operationalize them in their instruction.

In terms of language and theory, the definition for this set of teachers for social language appears to be framed mostly in situational contexts and through relationships with others. It is de-emphasized in instruction by this group of secondary teachers. Cummins's concept of BICS, basic interpersonal communicative skills (1979), is evidenced here in the responses of teachers, however, his concept of being on a type of continuum of contextual support, is not. Social language development is more often described as being limited to everyday basic encounters and/or within the immediate environment, but its description does not bridge to academic language. The idea of learning to talk as a means of getting to talking, reading, writing, to learn (Westby, 1985) also is not, for the most part, evidenced in teachers' descriptions.

Academic language definitions are representative of perspectives which hypothesize that there are language functions and structures which are specific to content areas and classrooms (Chamot \& O'Malley, 1986; Hamayan \& Perlman, 1990), as well as being defined by cognitive demand (Cummins, 1981; Snow, Cancino, DeTemple, \& 
Schley, 1991). A variety of theories are present in teachers' constructs, which they then operationalize into their instruction.

\section{Implications from Teacher Population}

South Florida is well known for its diversity of cultures and linguistic backgrounds. Initially, it was surprising that "native linguistic support" was one of the least frequently used strategies. Since there was no significant difference in terms of teachers' own native language backgrounds for this particular strategy, it cannot be said that this is an example of linguistic hegemony. Nearly $60 \%$ of all respondents were not native English language speakers. The non-usage of native language support may be indicative, however, that some teachers feel not giving support is a way of providing an immersion experience. They may believe that this forces or speeds up acquisition. Another possibility, is that some teachers may not view native linguistic support as a viable strategy to facilitate understanding in English language acquisition. They do not understand how knowledge may transfer or how the use of the native language can aid in comprehensibility of basic concepts. Perhaps there is also the problem determining when native linguistic support is too much and therefore counterproductive to acquisition. In this case, teachers may prefer to err on the side of caution. This wariness seems possible considering another unexpected result that arose from the interviews.

Teachers were recorded and after the structured interviews were completed, many wanted to talk, but not on tape. Over a period of time, it was noticed that teachers wanted very much to know if their definitions, their constructs, were the "correct" ones, the "right" ones. An underlying theme of "I must get it right for these kids" echoed over and over again. The desire to have dialogue was apparent in many of the written 
questionnaires as well. Besides answering questions, many teachers wrote long personal notes or letters about their frustrations, about their desire to do the very best for these students. Again, doubts about how to best instruct students resonated throughout the questionnaires and the interviews. Anxiety about students being able to acquire sufficient academic language in secondary school was a constant theme in these discussions. Several teachers forfeited anonymity on the questionnaires in order to be contacted, even going as so far as providing their home address and phone number. Additionally, several of the interviewees noted that they had taken their questionnaires and gone to other teachers and colleagues to discuss them and had been able to have meaningful dialogue in the process of completing them.

\section{Conclusions}

Based on this study, it appears that ESOL teachers need to have clear constructs of language. They need to be afforded the opportunity either in their educational preparation or through professional development to develop their definitions of social and academic language. In teachers' training sufficient focus must be given to language development so teachers may construct their definitions based on current research and knowledge in the field. Their understanding of language should reflect what is current in second language acquisition particularly since the field itself is relatively young and developing rapidly. Based on findings presented in this study in combination with a review of other research, conceptualization of the dichotomous relationship of social and academic language that has been previously theorized may need to be revisited. Rather than two separate spheres or dimensions, Figure 2 shows the aspects of social and academic language as overlapping aspects on a continuum of language 


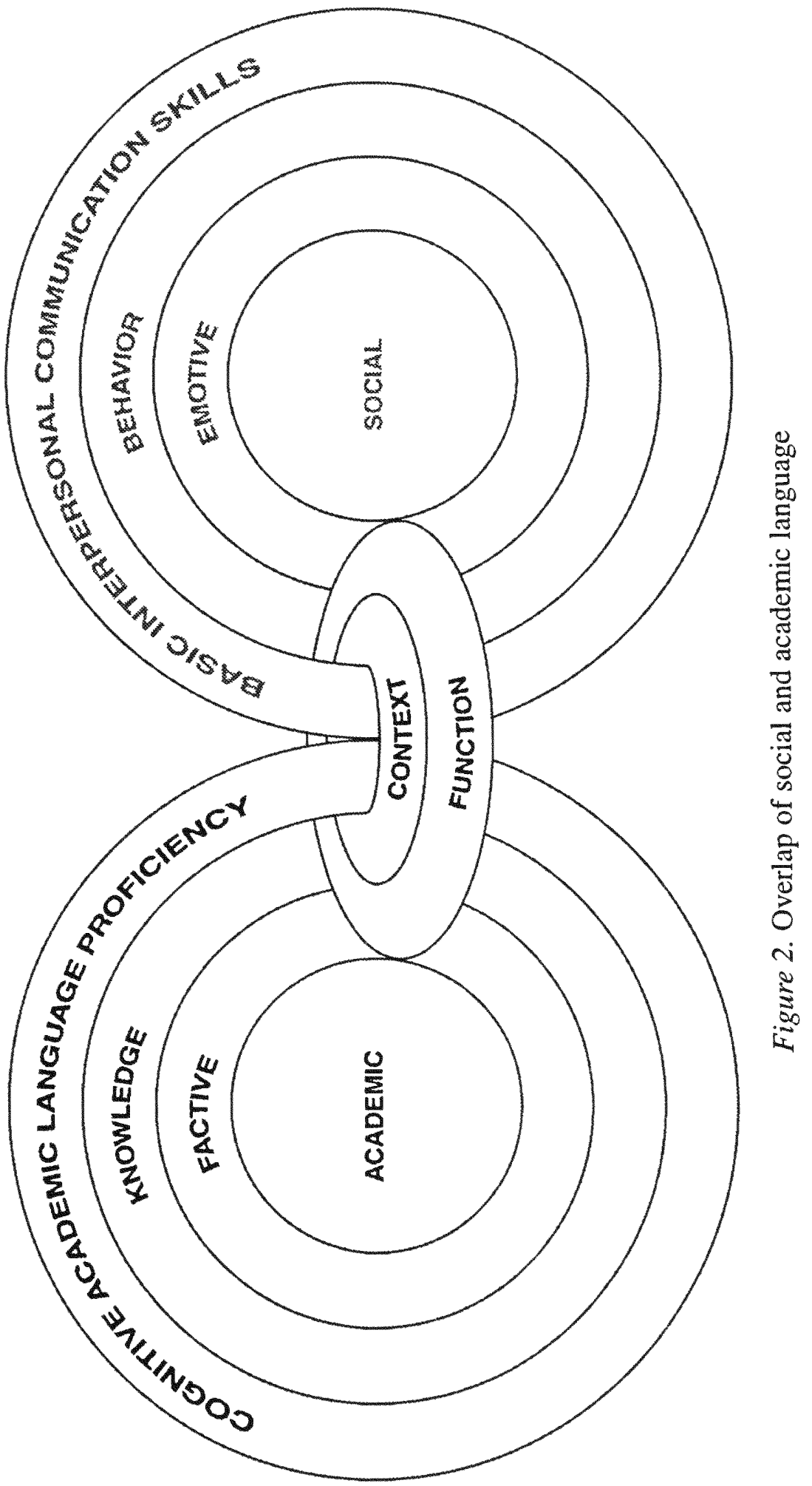


development intersected by context and function. Context and function operate separately or together along the continuum that includes aspects of both social and academic language. This conceptualization may explain to some degree the difficulty that teachers have in defining social and academic language or choosing examples illustrating both constructs.

Secondary ESOL teachers need to instruct for both aspects of language, not neglecting the social for the academic. This poses quite a dilemma, which was articulated by teachers' who are concerned over how to have these students acquire all they need in the short time left in their formal schooling.

Teachers also need to have a firm understanding of what is strategy and what is task. Congruence between instructional intent and delivery needs to be a primary focus for teachers of LEP students. However, this is not just the domain of ESOL teachers, but for any teacher who instructs LEP students. Moreover, all teachers need to be aware of social and academic language and the importance of developing these aspects of language.

\section{Implications for Practice}

Proficiency in academic language or language which is decontextualized is tantamount to academic achievement for LEP students. There is no denying the importance of academic language development for secondary LEP students. Since there is limited time for these students to develop the requisite skills needed to be successful academically, there is a tremendous need to concentrate efforts on academic language. However, the development of social language can not be abandoned if students are going to be prepared to participate in United States society and culture. Clarifying constructs 
should foster better understandings of both aspects of language development. Helping teachers to understand that language development is on a continuum with overlapping aspects of social and academic language is important to teachers creating clear constructs of language. In turn, these constructs are critical to instruction. Based on their understanding of language strategies can more readily be chosen to facilitate language acquisition. With clearer constructs, teachers are more likely to be able to provide instruction that promotes both social and academic language, and create a convergence of content, context, task, and form to develop LEP students' English language proficiency. Implication of Definition

Definitions were a significant focus of this study. Figure 3 shows the confluence of definition. Definitions of language are constructed and from them policy is made. The decisions of policy makers in turn affect the expectations of student achievement. This is the top down aspect of definition. The bottom up aspect is teacher definition. Teachers'definitions, whether based on professional preparation or pedagogical experience, affect their instruction, which in turn affects student achievement. These two vectors lead to expectations of student achievement. Definition should be informed from the most current research and cycle from pole to pole. What is needed to assure that the expectations for student achievement are realized is an agreement of definition at both poles.

\section{Recommendations}

There are four specific recommendations as a result of the study. First, despite the district's active provision of professional development activities through teacher education courses, workshops, and special ESOL summer training academies, there are 
Policy

$\downarrow$

$\downarrow$

Expectations of Student Achievement

$\uparrow$

$\uparrow$

Instruction

$\uparrow$

$\uparrow$

Teacher Definition

Figure 3. Influence of definition on policy and instruction.

still teachers who have not availed themselves of the opportunities to develop professionally. The consistent use of specific strategies across the district speaks well of the level of professional development heretofore. However, there needs to be a concerted effort to reach those who have not participated in professional development activities and those who have and could facilitate others' development while enhancing their own. Providing opportunities for those with evolving or evolved definitions, as well as those with incipient definitions, can raise the level of expertise while broadening it, with an 
anticipation of learning gains to be made by LEP students. In light of the comments of so many of the teachers wanting to dialogue, creating a professional network could be an outgrowth of this endeavor.

Secondly, development of materials and curricula needs to keep pace with the evolving conceptualizations of social and academic language and reflect current knowledge. Thirdly, university programs, which provide endorsement and certification in the field of English as a second language, may need to reexamine their own curricula and provide professional development to retrain their faculty. If ESOL teachers are graduating from education programs with insufficient development of language constructs, then those programs need to be evaluated and redesigned to facilitate the acquisition of this knowledge since it is vital to instruction and ultimately to student achievement. Additionally, all graduates of education programs should have knowledge of social and academic language and a basic understanding of second language acquisition and the importance of language development for all students.

Finally, the elements of definition, policy, and instruction must be in congruence and based on most current research and knowledge if achievement for LEP students is to be realized.

\section{Recommendations for Future Studies}

Further studies might examine the use of specific strategies for particular levels of English language proficiency. Additionally, it may be important to examine the dynamics of having multiple levels within the same classroom, particularly in relation to strategy use. Moreover, future studies might focus on the acquisition of social language for LEP students at the secondary level. Ultimately, research on the most effective 
strategies for development of social, as well as academic language at the secondary level, needs to be explored. 


\section{LIST OF REFERENCES}

Allen, P., Swain, M., Harley, B. \& Cummins, J. (1990). Aspects of classroom treatment: toward a more comprehensive view of second language education. In M. H. Long \& J.C. Richards (Series Eds.) \& Harley, B., Allen, P., Cummins, J. \& Swain, M. (Vol. Eds.), Cambridge Applied Linguistic Series. The Development of Second Language Proficiency (pp. 57 - 81). Cambridge: Cambridge University Press.

Anstrom, K. (1996). Defining the limited-English proficient student Population. [Electronic version]. Directions in Language and Education National Clearinghouse of Bilingual Education 1,(9). Retrieved December 3, 2000, from http://www.ncbe.gwu.edu/ncbepubs/directions/09.htm

Argyis, C. \& Schon, D.A. (1974). Theory in Practice. San Francisco: Jossey-Bass Publishers.

August, D. (Ed.). (1994). For all students: Limited english proficiency students and goals 2000. NCBE Focus: Occasional Papers in Bilingual Education, (10). http://www.ncbe.gwu.edu/ncbepubs/focus/focus 10. htm

Asher, J. (1982). Learning another language through actions: The complete teacher's guidebook. ( $2^{\text {nd }}$ ed.). Los Gatos, CA: Sky Oaks Productions, Inc.

Au, K.H. (1993). Literacy Instruction in Multicultural Settings. Fort Worth, TX: Harcourt Brace College Publishers.

Bialystok, E. (1978). A theoretical model of second language learning. Language Learning 28, $69-83$.

Bialystok, E. (1991). Metalinguistic dimensions of bilingual language proficiency. In E. Bialystok (Ed.), Language processing in bilingual children (pp. $113-140$ ). Cambridge: University of Cambridge Press.

Canale, M. \& Swain, M. (1980). Theoretical bases of communicative approaches to second language teaching and testing. Applied Linguistics, 1 (1), 1-47.

Chamot, A.U. (n.d.). Changing Instruction for language minority students to achieve national goals. Third National Research Symposium on Limited English Proficient Student Issues. Retrieved February 8, 2001, from http://www.ncbe.gwu.edu/ncbepus/symposia/third/chamot.htm

Chamot, A.U. \& O'Malley, J. M. (1986). A cognitive academic language learning approach: An ESL content-based curriculum. Wheaton, MD: National Clearinghouse for Bilingual Education. 
Chamot, A.U. \& O'Malley, J.M. (1987). The cognitive academic language learning approach: A bridge to the mainstream. TESOL Quarterly, 2l(2), 227-249.

Cheung, O. \& Solomon, L. W. (1991). Summary of state practices concerning the assessment of and the data collection about limited english proficient (lep) students. Washington, D.C.: Council of Chief State School Officers

Collier, V. (1987). Age and rate of acquisition of second language for academic purposes. TESOL Quarterly 21 (4), 617-640.

Constantino, R. (1994). A study concerning instruction of ESL students comparing allEnglish classroom teacher knowledge and English as a second language teacher knowledge. Journal of Educational Issues of Language Minority Students, 13, 37-57.

Cummins, J. (1979). Cognitive/academic language proficiency, linguistic interdependence, the optimum age question and some other matters. Working Papers on Bilingualism, 19, 121 - 129.

Cummins, J. (1979a). Linguistic interdependence and the educational development of bilingual children. Review of Educational Research 49, 222-251.

Cummins, J. (1980). The cross-lingual dimensions of language proficiency: Implications for bilingual education and the optimal age issue. TESOL Quarterly 14 (2), $175-187$.

Cummins, J. (1981). The role of primary language development in promoting educational success for language minority students. In California State Department of Education (Ed). Schooling and language minority students: a theoretical framework. Los Angeles: Evaluation, Dissemination and Assessment Center, California State University.

Cummins, J. (1984). Bilingualism and special education: Issues in assessment and pedagogy. Clevedon, England: Multilingual Matters.

Cummins, J. (1991). Empowering minority students: A framework for intervention. In M. Minami \& B.P. Kennedy (Eds.), Language issues in literacy and bilingual/multicultural education (pp. 372 - 390). Cambridge, MA: Harvard Educational Review.

Cummins, J. (1992), Interdependence of first-and second-language proficiency in bilingual children. In $\mathrm{E}$. Bialystok (Ed.), Language processing in bilingual children (pp. 70-89). Cambridge: University of Cambridge Press. 
Cummins, J. (1996). Language proficiency, bilingualism and academic achievement. In P. A. Richard-Amato, Making It Happen: Interaction in the Second Language Classroom (pp. $429-442)\left(2^{\text {nd }}\right.$ ed.) White Plains, NY: Longman.

Cummins, J. (2000). Language, power, and pedagogy: Bilingual children in the crossfire. Clevedon, England: Multilingual Matters.

Denzin, N. K. \& Lincoln, U.S. (1998). Strategies of qualitative inquiry. Thousand Oaks, CA: Sage Publications, Inc.

DiCerbo, P. A., (2000). Framing effective practice: Topics and issues in education English language learners. $N C B E$. Retrieved May 4, 2001, from http://www.ncbe.gwu.edu/ncbepubs/tasynthesis/framing/into.htm

Dixon, C. \& Nessel, D. (1983). Language experience approach to reading (and writing). Hayward, CA: The Alemany Press.

Donaldson, M. (1978). Children's minds. New York: W.W. Norton.

Fradd, S. H. \& McGee, P. (1994). Instructional assessment: An integrative approach to evaluating student performance. Reading, MA: Addison-Wesley Publishing.

Fradd, S. H. \& Lee, O. (1998). Development of a knowledge base for ESOL teacher education. Teaching and Teacher Education 14 (7), (761 - 773).

Fradd, S. H. \& Vega, J. E. (1987). Legal considerations. In S.H. Fradd \& W. Tikunoff (Eds.), Bilingual Education and Bilingual Special Education (pp. 45 - 74). Boston: College Hill Publication.

Freeman, D. (1994). Knowing into doing: Teacher education and the problem of transfer. In L.C. S. Li, D. Mahoney, \& J. C. Richards (Eds.) Exploring second language teacher development (pp. 1-21). Hong Kong: City Polytechnic of Hong Kong.

Gay, L. R. (1996). Educational research: Competencies for analysis and application (5th ed.). Upper Saddle River, NJ: Prentice Hall.

Gersten, R. (1999). The changing face of bilingual education. Educational Leadership, $56,(7), 41-45$.

Gersten, R. \& Baker, S. (2000). What we know about effective instructional practices for English-language learners. Exceptional Children, 66 (4), 454-470.

Goals 2000: Educate America Act of 1994, P.L. 103 - 227. (1994). 
Goodman, K. S., Goodman, Y. M. \& Hood, G. W. J. (Eds). (1989). The whole language evaluation book. Portsmouth, HN: Heinemann Educational Books, Inc.

Hakuta, K. (1986). Mirror of language: the debate on bilingualism. New York: Basic Books.

Hakuta, K., Butler, Y. G. \& Witt, D. (2000). How long does it take English learners to attain proficiency?[Electronic version]. (Policy Rep. 2000-1). Stanford, California: University of California, Linguistic Minority Research Institute.

Halliday, M. A. K. (1975). Learning to mean. New York: Elsevier.

Halliday, M. A. K.(1978). Language as social semiotic. Baltimore: University Park Press.

Hamayan, E.V. \& Perlman, R. (1990). Helping language minority students after they exit from bilingual/ESL programs: A handbook for teachers. Washington D.C. National Clearinghouse for Bilingual Education.

Hampson, R. (2001, April 1). 1990s boom reminiscent of 1890s. USA Today. Retrieved April 13, 2001, from http://www.usatoday.com

Harklau, L. (1994). ESL versus mainstream classes: Contrasting L2 learning environments. TESOL Quarterly 28 (2), $241-272$.

Harley, B, Cummins, J., Swain, M. \& Allen, P. (1990). The nature of language proficiency. In M. H. Long \& J.C. Richards (Series Eds.) \& Harley, B., Allen, P., Cummins, J. \& Swain, M. (Vol. Eds.), Cambridge Applied Linguistics Series. The Development of Second Language Proficiency. (pp. 7 - 25). Cambridge: Cambridge University Press.

Heath, S. B. (1983). Woys with words: Language, life, and work in communities and classrooms. New York: Cambridge University Press.

Improving America's Schools Act of 1994, P. L.103-382 (1994).

Krashen, S. D. \& Terrell, T. D. (1983). The natural approach: Language acquisition in the classsroom. Oxford: Pergamon Press.

Kuhlman, N. \& Murray, D.E. (2000). Changing populations, changing needs in teacher preparation. In Snow, M.A. (Ed.), Implementing the ESL standards for pre-k-12 students through teacher education, (pp.33-48). Alexandria,VA: TESOL. 
Larsen-Freeman, D. \& Long, M. H. (1991). Second language acquisition research methodolgy. In C. N. Cadlin (Series Ed.) \& D. Freeman \& M. H. Long (Vol.Eds.), Applied Linguistics and Language Study Series. An Introduction to Second Language Acquisition Research, (pp.10-50). New York: Longman.

League of United Latin American Citizens (LULAC) et al. v. State Board of Education (SBE) et al. Consent Decree - English for Speakers of Other Languages Settlement Agreement (1990).

Lee, O. \& Fradd, S. H. (1996). Interactional patterns of linguistically diverse students and teachers: Insights for promoting science learning. Linguistics and Education: An International Research Journal, 8, 269 - 297.

Menken, K. \& Holmes, P. (2000). Ensuring English language learners' success: balancing teacher quantity with quality. In Framing Effective Practice: Topics and issues in education English language learners. [Electronic version] Washington, D.C.: National Clearinghouse for Bilingual Education.

Miami Dade County Public Schools Division of Bilingual Education and World Languages. (2001). Statistics. Retrieved November 3, 2001 from http:// www.dade.k12.fl.us/bfls/statistics.htm

Mitchell, D., Destino, T., \& Karan, R. (1997). Evaluation of English language development programs in the Santa Ana Unified School District: A report on data system reliability and statistical modeling of program impacts. Riverside, CA: California Educational Research Cooperative, University of California, Riverside.

McGroarty, M. (1984). Some meanings of communicative competence for second language students. TESOL Quarterly 18 (2), 257-272.

McKnight, A. \& Antunez, B. (1999). State survey of legislative requirements for educating limited English proficient students. Washington D.C: National Clearinghouse for Bilingual Education.

McKeon, D. (1994). When meeting "common"standards is uncommonly difficult. Educational Leadership, 51 (8), 45 - 49.

McLaughlin, B., Rossman, T., \& McLeod, B. (1983). Second language learning: An information-processing perspective. Language Learning 33, 135 - 158.

Miles, M. B. \& Huberman, A. M. (1994). Qualitative Data Analysis. (2 nd ed.). Thousand Oaks, CA: Sage Publications, Inc.

Mohan, B. (1990). LEP students and the integration of language and content: 
Knowledge structures and tasks. Proceedings of the First Research Symposium on Limited English Proficient Student Issues. Washington, D.C.: U.S.

Department of Education, Office of Bilingual Education and Minority Languages Affairs.

National Center for Education Statistics. (1996). Are limited English proficient (LEP) students being taught by teachers with LEP training? Washington, D.C.: U.S. Department of Education, National Center for Education Statistics.

Office of Multicultural Student Language Education (OMSLE). (2000). Performance standards for teachers of english for speakers of other languages. Retrieved from October 19, 2001 from http://www.firn.edu/doe/bin00011/perstand.htm

Oller, J. (1979). Language tests at school. London: Longman.

Oller, J. (1981). Language as Intelligence? Language Learning, 31 (2), 465 - 492.

Oller, J. \& Perkins, K. (Eds.). (1978). Language in education: Testing the tests. Rowley, MA: Newbury House.

Olson, D. R. (1977). From utterance to text: the bias of language in speech and writing. Harvard Educational Review 47 (3), 257 - 281.

Patton, M. Q. (1990). Qualitative evaluation and research methods (2nd ed.) Newbury Park. CA: Sage Publishers, Inc.

President's Advisory Commission on Educational Excellence for Hispanic Americans. (2000). Creating the will: Hispanics achieving educational excellence. Washington, D.C.: Author.

Ruiz-de-Velasco, J., Fix, M., \& Chu Clewell, B. (2000). Overlooked and underserved: Immigrant students in U.S. secondary schools. Washington, D. C. : Urban Institute. http://www.urban.org/pdfs/overlooked.pdf.

Short, D. (2000). Using the ESL standards for curriculum development. In Snow, M.A.(Ed.) Implementing the ESL standards for pre $k-12$ students through teacher education, (103-136). Alexandria, VA: TESOL, Inc.

Solomon, J. \& Rhodes, N. (1995). Conceptualizing Academic Language. Santa Cruz: National Center for Research on Cultural Diversity and Second Language Learning.

Solomon, J. \& Rhodes, N. (1996a, Winter). Assessing academic language: Results of a survey. Elementary Education Newsletter, 7. 
Solomon, J. \& Rhodes, N. (1996b). Assessing academic language: Results of a survey. TESOL Journal, 5 -8.

Snow, C.E. (1983). Literacy and language: relationships during pre-school years. Harvard Educational Review 53, 165 - 189.

Snow, C.E., Cancino, H., DeTemple, J. \& Schley, S. (1991). Giving formal definitions: A linguistic or metalinguistic skill? In E. Bialystok (Ed.), Language processing in bilingual children (pp. 90-112). Cambridge: University of Cambridge Press.

Swain, M. (1981). Time and timing in bilingual education. Language Learning 31 (1), $1-15$.

Tashakkori, A. \& Teddlie, C. (1998). Mixed methodology: Combining quantitative and qualitative approaches. Thousand Oaks, CA: Sage Publications, Inc.

Teachers of English as a Second Language, Inc. (TESOL). (1999, August). TESOL statement on the acquisition of academic proficiency

in English. Retrieved from October 21, 2001, from

http://www.tesol.org/assoc/statements/acqproficiency.html

Teachers of English as a Second Language, Inc. (TESOL). (1997). ESL standards for pre-k-12 students. Alexandria, VA: Author.

Tikunoff, W. J. (1987). Mediation of instruction to obtain equality of effectiveness. In Fradd, S. H. \& Tikunoff, W. J. (Eds.), Bilingual education and bilingual special education, (pp. 99 - 132). Boston: College Hill Publication.

Transforming Florida Schools, CS/HB 751. (1999).

Vygotsky, L. S. (1962). Thought and Language. (Hanfmann, E. \& Vakar, G. Trans.). Cambridge, MA: Massachusetts Institute of Technology Press. (Original work published 1939).

Westby, C. E. (1985). Learning to talk - talking to learn: Oral/literate language differences. In C.S. Simon (Ed.). Communication skills and classroom success (pp. 181 -213). San Diego: College Hill Press.

Wong Fillmore, L. \& Snow, C. E. (2000, August 23). What teachers need to know about language. Washington, D.C.: National Clearinghouse for Bilingual Education. 


\section{APPENDICES}




\section{APPENDIX A}

1. How many years experience do you have teaching ESOL?

Elementary yrs. Middle yrs. High School yrs. Adult rs.

2. Circle all degrees earned and indicate specific major below degree

$\begin{array}{llll}\text { Bachelors } & \text { Masters } & \text { Specialist } & \text { Doctorate } \\ \text { Major } & \text { Major } & \text { Major } & \text { Major }\end{array}$

3. Indicate how you are ESOL endorsed: (circle response) College credit/degree TEC credits Not endorsed

4. Native Language (circle)

English French Haitian-Creole Portuguese Spanish Other

5. How are your classes grouped? (circle)

only beginners only intermediates only advanced

mixed levels (ie. beginners with intermediates) all levels together

Circle letter of answer for each of the following questions.

6. Academic language proficiency
a. develops more rapidly than social language
b. is acquired at the same rate as social language
c. takes longer to develop than social language

7. Academic language
a. is only in written form
b. includes oral and written forms
c. emphasizes reading comprehension

8. Social language
a. occurs between students
b. is more dependent on a specific context
c. is more abstract than academic language

9. Social language

a. makes learning content more enjoyable and creates a positive leaming environment

b. is all oral language

c. is more explicit than academic language

10. How do you differentiate between social and academic language? 
11. Give two language examples of social language.

12. Give two language examples of academic language.

13. Describe how you would instruct for academic language development with each of the following groups:

beginning LEP students.

intermediate LEP students:

advanced LEP Students:

multilevel LEP Students: 
14. Label each of the following as representing an example of social or academic language.
a. responding orally to a teacher's school related talk
b. giving a definition
c. asking for assistance on an assignment or classroom task
d. responding to how a poem makes you feel
e. using contextual cues to gain understanding
f. reading a story and retelling it through drama or pictures
g. creating a chart showing data and presenting it to a group
h. taking notes to summarize material
i. interacting with a partner or in a cooperative group
j. explaining the reason for an absence

\begin{abstract}
social academic
social academic

social academic

social academic

social academic

social academic

social academic

social academic

social academic

social academic
\end{abstract}

15. How often do you use the following strategies for LEP students?

$$
\begin{array}{ll}
0=\text { never or almost never } & 1=\text { occasionally (once a mo } \\
2=\text { frequently (bi-weekly or more) } & 3=\text { daily or almost daily }
\end{array}
$$
a. text adaptation
0123
b. specific vocabulary use (ten or less words)
c. visuals or grapWc organizers
d. demonstrations
e. manipulatives
0123
f. cooperative groups
0123
0123
g. peer partners
0123

0123

0123

h. native language support within class

i. adjusting cognitive and language demands according to task difficulty

$\mathrm{j}$. adjusting cognitive and language deniands according to linguistic difficulty

1. think alouds $\quad 0123$

in. role play and drama

Additional comments: 


\section{MIAMI-DADE COUNTY PUBLIC SCHOOLS}

OFFICE OF EVALUATION \& RESEARCH 1500 BISCAYNE BOULEVARD, SUITE 225 MIAMI, FLORIDA 33132

Roger C. Cuevas

Superintendent of Schools

Robert A. Collins

Executive Director

Office of Evaluation and Research

(305) 995-7529

FAX: 996-7571
Dade County School Board Ms. Parts Tabares Heronan, Chair Dr. Michael M. Krop, Vioe-Chair Dr. Robert B. Ingram Ms. Betsy H. Kaplan Mrs. Manty Sabatf Morse Ms. JacqueWe V. Popper Mir. Demetrio Perez, Jr., M.S. Dr. Marta Perez Dr. Solomon C. Stinson

March 29, 2001

Judy Chin

11151 S.W. 145 Court

Miami, Florida 33186

Dear Ms. Chin:

I am pleased to inform you that the Research Review Committee of the Miami-Dade County Public Schools (MDCPS) has approved your request to conduct the study, "What Secondary ESOL Teachers Know about Social and Academic Language and Instructional Strategies for Limited English Proficient Students." The approval is granted with the following conditions:

1. A copy of this approval letter must be forwarded to each recipient of the survey.

2. The participation of all subjects is voluntary.

3. The anonymity and confidentiality of all subjects must be assured.

4. The study will involve approximately 320 ESOL teachers in the district.

5. The MDCPS internal school mail system cannot be used in conducting the study.

It should be emphasized that the approval of the Research Review Committee does not constitute an endorsement of the study. It is simply a permission to request the voluntary cooperation in the study of individuals associated with the MDCPS. It is your responsibility to ensure that appropriate procedures are followed in requesting an individual's cooperation, and that all aspects of the 
study are conducted in a professional manner. With regard to the latter, make certain that all documents and instruments distributed within the MDCPS as a part of the study are carefully edited.

The computer-generated data for the study will be provided by Ms. Gisela Feild of the Division of Data Quality Management of the MDCPS. Contact her at (305) 995-7511 to arrange a meeting to review your request and determine the cost.

The approval number for your study is 742 . This number should be used in all communications to clearly identify the study as approved by the Research Review Committee. The approval expires on June 30,2002. During the approval period, the study must adhere to the design, procedures and instruments which were submitted to the Research Review Committee. If there are any changes in the study as it relates to the MDCPS, it may be necessary to resubmit your request to the committee. Failure to notify me of such a change may result in the cancellation of the approval.

If you have any questions, please call me at (305) 995-7501. Finally, remember to forward an abstract of the study when it is complete. On behalf of the Research Review Committee, I want to wish you every success with your study.

Sincerely,

Joseph J. Gomez, Ph.D.

Chairperson

Research Review Committee

JJG:cg

cc: Ms. Gisela Feild 
Dear

I have been fortunate to work with many of you, either through workshops given by the district or in the ESOL Summer Academy. I am a doctoral student in Instructional Leadership at Florida International University conducting research on social and academic language and instructional strategies used for secondary LEP students.

I would greatly appreciate your completing the enclosed survey. Your responses will provide information on our current knowledge of social and academic language and instructional strategies used for secondary LEP students. The information on the survey is anonymous. Included is a postcard which when returned verifies who has responded without matching the survey to the postcard. There is a place on the card for you to indicate your willingness to be briefly interviewed at a future time. If you have any questions, please feel free to contact me, Judy Chin, at 305-388-5632 or if you have questions about the research please contact Dr. Bernard Gerstman, Institutional Review Board Chairperson, at 305-348-3115.

I am fully aware of all your responsibilities and the demands that are placed on you, especially at this time of year, since I too, am in the classroom. Hopefully, the approximately twenty minutes of time it will take you to answer this survey will be of value to you in reflecting on your ideas about social and academic language and your own practice. Please complete the survey as soon as possible and return it in the envelope provided. Mail the postcard separately. Once again, thank you for completing the survey. Your time, knowledge and expertise are invaluable to this project.

Sincerely,

Judy Chin

Doctoral Student

Florida International University 


\section{APPENDIX D}

Interview protocol

1. How do you differentiate between social and academic language?

2. Do you/how do you instruct for social language?

3. Can you give me an example of how you instruct for social language?

4. How do you instruct for academic language?

5. Can you give me an example of how you instruct for academic language?

6. How do instruct for academic language for different levels?

7. If someone came into your classroom what would they see you doing to instruct for academic language?

8. Would I be able to visit your classroom to observe you at some time in the future? 


\section{JUDY CHIN}

\section{Educational Background}

Ms.Ed. in TESOL, University of Miami, December 1993

B.A. in Communication and Theater, University of Colorado, June 1973

\section{Professional Experience}

ESOL Teacher for Dade County Public Schools 1989 - Present

Member of National Advisory Committee and

Regional Coordinator for Teacher Assessment

Development for ENL (English as a New

Language) for National Board Certification

$1998-1999$

TESOL Adjunct lecturer at University of Miami

$1999-2000$

Visiting Lecturer Adams State College, Alamosa, 1999 (summer) Colorado

\section{Publications}

The Literacy Continuum, In Classroom Inclusion Strategies for Students Learning English, edited by Sandra H. Fradd, Ph.D. and Janette Klinger, Ph.D., Tucson, Arizona: Communication Skill Builders, 1995.

Organizational Memberships

TESOL

Sunshine State TESOL

Returned Peace Corps Volunteers of South Florida Cultural Affairs Council of South Miami 